Final Report on Project Number

\title{
DE-FG07-01ID14119
}

\section{LIQUID METAL BOND FOR IMPROVED HEAT TRANSFER IN LWR FUEL RODS}

Principal Investigator:

Professor Donald Olander

University of California, Berkeley

Period Covered: June $4^{\text {th }}, 2001$ - June $3^{\text {rd }}, 2005$ 


\begin{abstract}
A liquid metal (LM) consisting of 1/3 weight fraction each of $\mathrm{Pb}, \mathrm{Sn}$, and $\mathrm{Bi}$ has been proposed as the bonding substance in the pellet-cladding gap in place of He. The LM bond eliminates the large $\Delta \mathrm{T}$ over the pre-closure gap which is characteristic of helium-bonded fuel elements. Because the LM does not wet either $\mathrm{UO}_{2}$ or Zircaloy, simply loading fuel pellets into a cladding tube containing LM at atmospheric pressure leaves unfilled regions (voids) in the bond. The HEATING 7.3 heat transfer code indicates that these void spaces lead to local fuel hot spots. Surface treatments yielded no improvement in wetting properties. Voids were eliminated during fabrication by first evacuating the rod loaded with solid alloy and a fuel stack, melting the alloy, pushing down the fuel stack to drive the LM into the gap, and finally applying at least 5 atm He overpressure. A 4-m long full-scale fuel rod using this technique of fabrication was successfully demonstrated. A destructive examination showed that the bonding in at least $25 \%$ of the fuel rod remained completely intact (the remaining fuel rod awaits the destructive examination). The pre-closure reduction in fuel temperature in the LMbonded rod slowed fission-gas diffusion in the grain and so increased the time required to saturate the grain boundaries. Numerical calculations compared the delay in the onset of fission gas release in LM-bonded rods compared to He-bonded rods. The delay afforded by LM-bonding could be as high as $\sim 1$ year and as low as 2 days. Application to commercial fuel manufacturing requires only minor modifications to the existing fabrication line. The most suitable NDE technique utilizes a collimated X-ray beam to probe edge-on the region between the pellet surface and the cladding ID.
\end{abstract}




\section{INTRODUCTION}

In light water reactors, a helium-filled gap between the fuel and the cladding accommodates fuel swelling and cladding creep-down. However, the low thermal conductivity of helium results in a large temperature drop over the gap before closure occurs. To remedy this situation, Wright et al proposed "bonding" the gap with a liquid metal (LM) [1, 2]. The LM (33 wt\% each of lead, tin, and bismuth) was chosen for its low melting point $\left(\sim 120^{\circ} \mathrm{C}\right)$, its lack of chemical reactivity with $\mathrm{UO}_{2}$ and water, and its high thermal conductivity ( 100 times that of He). The thermal resistance of the LMbonded gap is essentially nil, irrespective of the gap thickness [2, 3]. The presence of $\mathrm{Pb}$, $\mathrm{Sn}$, and $\mathrm{Bi}$ in the gap gives no appreciable neutronic penalty because of their low thermal neutron absorption.

Prior to closure of a helium-bonded gap, the centerline fuel temperature can be hundreds of degrees hotter than that with a LM-bonded gap at the same linear heat rating. In addition to reducing the stored energy in the fuel, the LM bond permits initial gap thicknesses sufficiently large to totally avoid fuel-cladding mechanical interaction over the fuel element lifetime. With modestly creepdown-resistant cladding, a $150 \mu \mathrm{m}$ initial cold radial LM-bonded gap does not close until $\sim 60 \mathrm{MWd} / \mathrm{kgU}^{1}$. By comparison, the usual helium hot gap thickness in LWRs is half of this value, and gap closure occurs at the end of the first cycle. The reduction in fuel temperature also delays the onset of fission gas release anywhere from 1-2 days to $\sim 1$ year [4].

Liquid metal in the gap can also prevent massive secondary hydriding by impeding steam ingress into the gap following cladding failure by, for example, grid-to-rod fretting. The metal in the gap above the breach is blown into the plenum by the incoming steam. The metal below the breach is left intact and protects this portion of the cladding from secondary hydriding. The LM bond also prevents fission fragment recoils and deleterious fission products such as iodine from reaching the cladding ID.

The fuel rod with a LM-bonded gap has a top plenum similar to that in a conventional fuel element. In addition to the usual role as a repository for released fission gas, the plenum collects LM which is squeezed out of the gap due to pellet swelling.

\footnotetext{
${ }^{1}$ ANATECH company ran the FALCON fuel behavior code for this purpose.
} 
The bond is liquid during reactor operation and no adverse effects of freeze-thaw cycling in short $\mathrm{UO}_{2} /$ Zry fuel elements have been found.

Wright et. al. [2] extensively studied the material compatibility by having LM in contact with zircaloy tubes. Alumina pellets were used as surrogates of $\mathrm{UO}_{2}$. For specimen tested at $400{ }^{\circ} \mathrm{C}$ for 3500 hours (to simulate standard operating conditions), the average loss in Zry wall thickness was less than $0.3 \%$. At $657{ }^{\circ} \mathrm{C}$ for 24 hours (to simulate LOCA), the average Zry wall thickness loss was less than $4 \%$. Thus, from the material compatibility viewpoint, the negligible cladding wall thickness loss makes the eutectic LM compound an ideal choice for the pellet-cladding-gap bonding agent. A reaction layer attached to the Zry tube was observed under optical microscope. Results from an electron beam microprobe indicated a $\mathrm{ZrSn}_{2}$ intermetallic compound. The authors concluded that the compound acts as a diffusion barrier against Zr or Sn or both.

The objectives of the work are: i) To produce an intact LM bond between a 4-m stack of standard $\mathrm{LWR} \mathrm{UO}_{2}$ fuel pellets and Zircaloy cladding; ii) To evaluate the effect of imperfect bonding on fuel temperature; iii) To determine the effect of the LM bond on reducing (or delaying) fission gas release; iv) To determine the most suitable NDE method to probe the quality of the LM bond; v) To demonstrate that full-size LM-bonded fuel rods can be manufactured with only modest modifications of commercial fuel element fabrication facilities. 


\section{EXPERIMENTAL}

\section{II.A. Surface Treatment}

Due to the poor wetting properties of the $\mathrm{LM}$ with both $\mathrm{Zry}^{2}$ and $\mathrm{UO}_{2}$, voids (vacuum spaces) form in the gap during fabrication. In addition, trapped air bubbles also disrupt the continuity of LM in the gap. The first attempt to improve the wetting properties of surfaces was to perform surface treatments by etching and sand blasting. Zircaloy sheets

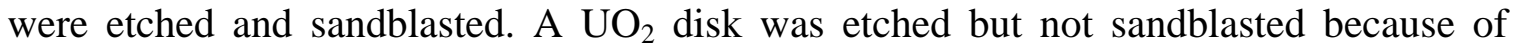
radiation contamination concern at the facility. The etching solution and etching time for each material are summarized in the first column in Table 1. For each conditioned material, a $130{ }^{\circ} \mathrm{C}$ molten LM was dropped onto the surface and allowed to solidify. It was assumed that the wetting properties of LM did not change when solidified. The contact angle was measured by the angle the LM made with the surface, shown in Figure 1. The liquid metal wets a surface if the contact angle is less than $90^{\circ}$. It is evident that no surface preparation technique could induce the LM to wet either Zry or $\mathrm{UO}_{2}$.

\section{II.A. Small-scale glass-clad apparatus}

Continuity of LM in the gap is disrupted by trapped air bubbles or voids formed as a consequence of the poor wetting properties of $\mathrm{UO}_{2}$ and Zry. An apparatus using glass cladding was constructed to permit observation of voids/bubbles in the LM-bonded gap at various stages of fabrication. Figure 2 shows the layout of the apparatus and Figs 3(a) and 3(b) are photos of the assembly, which consists of a glass tube connected to a top pressure/vacuum fitting. The ID of the tube is chosen to provide a radial gap between 100 and $200 \mu \mathrm{m}$ when stacked with 10 PWR or BWR fuel pellets. All pellets and cladding are as-fabricated with no surface treatment except for acetone cleaning. In air, voids and bubbles are present in the gap. In vacuum, only voids containing no gas are present. The unit is brought to $150{ }^{\circ} \mathrm{C}$ in a half-clamshell heater. The procedure is as follows: Sufficient metal is added to the tube so that LM fills the gap when the $\mathrm{UO}_{2}$ pellets are inserted. The tube can be initially air-filled (at $1 \mathrm{~atm}$ ) or evacuated. In the former case,

\footnotetext{
${ }^{2}$ The poor wetting by the LM is probably due to the thin native oxide layer on Zry ( $7 \mathrm{~nm}$ thick).
} 
voids and bubbles are present in the gap. In the latter case, only voids containing no gas are present.

For dished PWR pellets, application of $\sim 7$ atm to the interior of the tube after submerging pellets in the LM collapses both voids and bubbles and produces a perfect LM bond. Figure 4 shows the void fraction vs. applied pressure for three different gap sizes. The void fraction is defined as the area occupied by the voids/bubbles divided by the circumferential area of the entire pellet stack. As can be observed in the plot, more voids/bubbles are initially present for the small gap size than for the bigger ones. With increasing pressure, the unfilled regions collapse regardless of the gap size.

Figures 5a - 5d illustrate the progressive collapse of four voids with pressurization. The 10 pellets were the dished PWR type with a 145-micron radial gap.

For flat-end BWR pellets loaded into air-filled tubes, application of pressure failed to produce a perfect bond. No dished regions were available to accommodate the air bubbles trapped in the gap. Figure 6 shows the incomplete LM binding. With BWR pellets, initial evacuation of the tube is required to prevent trapping of residual air. Subsequent pressurization eliminates any voids present.

\section{II.B. Small Zry-clad apparatus}

A set of 10 PWR pellets were inserted into LM-containing Zircaloy cladding using the same loading procedure. To expose the LM and fuel pellets, the cladding was milled axially at locations roughly $180^{\circ}$ apart and the half-tubes pulled away. A perfect LM bond was observed throughout the length of the pellet stack, as shown in Fig 7.

\section{II.C. Liquid Metal Penetration into Cracks}

In reactor, the fuel pellets are cracked due to thermal stresses. The ability of pressurization to push LM into cracks in the pellet was investigated. Radial cracks shown in Fig 8 were created in a $\mathrm{UO}_{2}$ pellet by repeated thermal quenches. The cracked pellet was loaded into the LM-filled glass tube and pressurized to $7 \mathrm{~atm}$. Visual observation of disks cut from the pellet after this procedure confirmed that liquid metal entered all cracks, some of which extended to the center of the pellet. Figure 9 shows a crack on the fuel surface that provided a pathway for LM to enter the fuel interior. Figure 10 shows a 
cross-section of the pellet with cracks filled with LM. Observation under an optical microscope revealed LM in cracks as narrow as 3 microns. The LM internal to the pellet increases the effective thermal conductivity of the fuel.

\section{II.D. Simulation of Fission Gas Release}

During irradiation, fission gas released from the fuel will form bubbles in the liquid metal. These unfilled regions will thermally insulate the portions of the pellet in contact with the bubble, causing local overheating. It is therefore of interest to know if rod internal pressure can prevent fission-gas bubble formation. To simulate the fission gas release into the gap, porous alumina pellets were used as surrogates for the actual oxide pellet ${ }^{3}$.

To test the ability of the porous pellets to release air with increasing temperature, as predicted by ideal gas law, the following experiment was conducted. Seven pellets each $1.5 \mathrm{~cm}$ in height were pushed into a glass tube filled with water. The combination of the pellet diameter and the tube inner diameter gave a radial gap of $90 \mu \mathrm{m}$. The open porosity of the pellet was reported by the manufacturer ${ }^{4}$ to be $50 \%$. The end of the glass tube was closed with a Teflon plug and covered with Epoxy for added strength. The "fuel rod” was immersed in a water bath with an electric ceramic heater. A thermocouple submerged in the bath contacted the outside of the glass tube at its middle. When heated to $\sim 40{ }^{\circ} \mathrm{C}$, large air bubbles were observed to form in the gap region and finally rose to the top of the pellet stack.

The next step was to replace water with liquid metal. Commercial lard was used in the temperature bath instead of water, whose boiling point is below that needed to melt the alloy ( $130{ }^{\circ} \mathrm{C}$ ). The temperature of the bath was raised to $\sim 135{ }^{\circ} \mathrm{C}$ and the glass tube was $1 / 4$ filled with LM under atmospheric pressure. The porous pellets were pushed into the rod one at a time. The radial gap was still 90 microns. The top of the rod was capped with a pressure fitting and the rod was pressurized to $\sim 7 \mathrm{~atm}$ with nitrogen. All unfilled regions in the LM disappeared. The mean rod temperature was then raised to $190{ }^{\circ} \mathrm{C}$, no voids were observed at all during the temperature ramp.

\footnotetext{
${ }^{3}$ Release of fission gas from the actual fuel pellets can only be achieved by reactor irradiation

${ }^{4}$ Coors Tech Company.
} 
The pressure was reduced to 1 atm while the temperature was held at $190{ }^{\circ} \mathrm{C}$. Bubbles immediately formed, as can be seen in Fig. 11. The same test was performed two more times for repeatability, and the results were identical. A pyrex tube with different inner diameter yielding gap size of $\sim 140 \mu \mathrm{m}$ was also tested and the result was also identical.

The number of moles of air released out of the porous pellets at $190{ }^{\circ} \mathrm{C}$ and $1 \mathrm{~atm}$ is calculated to be $3.1 \times 10^{-5}$ moles/cm of pellet. For comparison purposes, assuming the LM-bonded fuel rod is burnt to $50 \mathrm{MWd} / \mathrm{kgU}$ and a $7 \%$ Xe release, the number of moles of xenon released is calculated to be $3 \times 10^{-5}$ moles/cm of fuel length. If the released fission gas congregates as big bubbles in the LM bond as seen in Fig. 11, it may cause the fuel to overheat. Discussion of the extent that the LM bond with Xe bubble can accommodate heat transfer without causing fuel overheating is discussed under Calculations section.

In a fuel rod irradiated in-reactor, released fission gases cannot be driven back into the $\mathrm{UO}_{2}$ matrix. However, at plenum pressure ( $40 \mathrm{~atm}$ at power), the gas may be pushed into cracks in pellets or into pellet-pellet interfaces. Thus the test performed in this study may or may not represent what would happen with released fission gas in an LM-bonded fuel element.

\section{II.E. Full-Scale Fabrication Demonstration}

A full-scale LM-bonded fuel rod apparatus was constructed, in the rig shown in Figure 12. It consists of a 4-meter long aluminum rail with heating tapes underneath the entire length. Thermocouples are installed at five locations along the length of the rail to ensure that the liquid metal does not freeze during filling of the fuel-cladding gap (see Fig. 13). A Plexiglas cover over the entire length prevents accidental physical contact with the hot aluminum rail and the Zry cladding. The apparatus is tilted slightly in order to prevent spillage of LM out of the open of the cladding tube.

A 4-m-long Zry tube is placed on the support rail with the bottom end closed by a Teflon plug. The ID of the cladding tube is $0.966 \mathrm{~cm}$ and the gap thicknesses (radial) are 70 and $120 \mu \mathrm{m}$ ( 2 pellet sizes were used). Sufficient bond metal is loaded into the cladding tube in chunk solid form so that, when melted, LM fills the entire gap and 
covers the topmost pellet by a few centimeters. For quality control (discussed later), a small amount of neutron-activated gold powder is dissolved in the LM prior to use. $\mathrm{UO}_{2}$ pellets are then pushed into the cladding tube one at a time to form a 3-m-long fuel stack. A pressure/vacuum-line sleeve is attached to the open end of the tube, which also accommodates a "push rod" to drive the fuel stack to the bottom of the cladding tube after the bond metal is melted. Figure 14 shows the open end of the apparatus.

The fabrication procedure is as follows: the heaters are turned on and the cladding held at $\sim 130{ }^{\circ} \mathrm{C}$ in order to insure melting of the bond metal. Air is evacuated from tube to a pressure of $\sim 0.01 \mathrm{~atm}$. The push rod is then used to drive the pellets through the LM to the bottom of the cladding tube. Simultaneously, LM rises and fills the fuel-cladding gap. Finally, the cladding is pressurized with $\sim 7 \mathrm{~atm}$ of helium. This procedure requires approximately 45 minutes. The heaters are turned off and the fuel rod allowed to cool to room temperature.

Except for the requirements of heating the tube and tilting the support rail by about $15^{\circ}$, the fabrication procedure is the same as that used in current fuel fabrication lines. The current commercial facilities are already equipped with provisions for evacuating the tubing and pre-pressurizing the fuel-loaded cladding tube. Conversion from He to LM in the fuel-cladding gap should not pose significant difficulties in industrial fabrication lines.

\section{II.F. Destructive examination of the full-scale fuel rod.}

It would be desirable to mill the cladding axially at locations roughly $180^{\circ}$ apart and pull the half-tubes away to show the LM bond inside the full-scale fuel rod. This procedure was performed on the 10-pellet miniature fuel rod (see Figs. 6(a) - 6(c)). However, this procedure proved to be unworkable on the full-length fuel element. The rod bulged at some locations and the milling head sometime cut into the $\mathrm{UO}_{2}$ pellets, causing (small) radiation contamination.

Consequently, another destructive examination technique was used. The full-scale fuel rod was cut by a low-speed diamond saw into 1-centimeter-long sections and the solidified bond-alloy "rings" at the top and bottom of each section were visually observed. Some sections were observed under optical microscope as well. If 
voids/bubbles were present, they would show up as a discontinuity in the metal ring. The work currently proceeded to $25 \%$ of the entire length (75 sections) and the metal bond was observed to be $100 \%$ intact in all sections. Figure 15 shows an optical microscope view of the metal bond ring. Work will continue until the entire length of the rod has been destructively examined.

\section{II.B. QUALITY CONTROL}

Obviously, cutting fuel rods into 300 pieces is not an optimum quality-control method. NDE is required.

\section{II.B.1 Eddy Current Test Method}

Two miniature Zry-clad fuel rods were eddy-current tested at EPRI's NDE center. The first rod was prepared by a technique that eliminated all voids in the LM bond. The second rod was intentionally prepared with some voids/bubbles in the LM. The specimens were later destructively examined (by axially milling the cladding $180^{\circ}$ apart and pulling the cladding away) to match the signals to the morphology of the exposed frozen gap metal. Figure 16 shows the encircling probe ${ }^{5}$ signal output (left) and the matching locations of the first specimen (right). The spike in the signal indicates that the technique can determine the transition from the empty part of the Zry tube to a region completely filled with LM, and from the region completely filled with LM to the region with $\mathrm{UO}_{2}$ and $\mathrm{LM}$ in the gap. The signal in the "pellet" region consists solely of noise.

Figure 17 shows the probe signal output (left) and the matching locations of the second specimen (right). The signal clearly responds to the metal-filled region, but fails to indicate the presence of voids in the pellet region.

Ideally, the signal should drop when passing over a void, which has poor conductivity compared to LM. The reason why it was not observed is most likely that the annulus of LM around the pellet is so thin ( 90 microns on average) compared to the cladding thickness (750 microns) that the $12 \%$ difference in local conductivity between voided and metal-filled regions cannot be picked up.

\footnotetext{
${ }^{5}$ The encircling probe is like a sleeve that slides along the length of the fuel rod.
} 
A pencil eddy-current probe was used to scan the length of the fuel rod along a straight line on the cladding. The signal from the probe was able to accurately pinpoint pellet-pellet interfaces, but it failed to locate voids.

In conclusion, the eddy current technique is not a suitable quality control technique for the present purpose.

\section{II.B.2 Irradiated Gold Tracer}

Detection of the $418 \mathrm{keV}$ gamma ray emitted from neutron-activated gold dissolved in the LM was investigated as a means of locating voids in the bond. The setup consisted of a Ge detector with a lead collimator with a $1 \times 2 \mathrm{~mm}$ opening. The fuel rod was moved axially and circumferentially in front of the collimator opening to detect voids by a drop in the gamma-ray signal. This method eliminates the signal degradation in the eddy-current method due to the presence of the cladding.

To establish a reference, a 10-pellet miniature glass fuel rod with irradiated gold dissolved in the LM was fabricated with voids intentionally left in the LM bond. Figure 18 shows the gamma ray signal from the void and LM-filled regions. It is evident that counts in locations with voids in the LM bond are at least 50\% lower than counts at locations where the LM bond is intact.

Figure 19 summarizes the counts measured at 50 locations around the entire length of the full-size fuel element from top (location 1) to bottom (location 50). Locations 1-6, which is in the half grayed-out region in the plot, contain only LM (no fuel) so the counts are uniformly high. The region from locations 7 onward contains fuel pellets. The norm of the normalized counts is $1.5 \pm 0.3$. There are no locations where signals fall below $50 \%$ of the norm. The variations in the signals in the LM-bonded regions in Figs. 18 and 19 are probably due to varying gap thicknesses due to off-center pellets and different pellet sizes. The results shown in Fig. 19 strongly suggest that no voids are present in the frozen metal bond. As discussed earlier, the destructive examination up to $25 \%$ of the fuel rod revealed $100 \%$ intact LM bond everywhere. Unfortunately, the activated-gold NDE method is not intended for use in industrial production. 


\section{II.B.3 X-Ray Photography}

An alternative method is to use a $180-200 \mathrm{kV} \mathrm{X-ray} \mathrm{to} \mathrm{detect} \mathrm{voids} \mathrm{edge-on} \mathrm{(see}$ Fig 20). X-Tek System Ltds in England conducted a preliminary test on a surrogate fuel rod consisting of a $10-\mathrm{cm}$ tungsten pellet stack (to closely match the $\mathrm{x}$-ray absorption properties of $\mathrm{UO}_{2}$ ) and LM with voids. The dummy fuel rod was rotated through 180 degrees to detect all voids as they come to the edge-on positions with the detector on both sides.

Figures 21(a) - 21(d) illustrate that voids are clearly seen edge-on in the LM between the outer tube and the fuel pellet. This technique can be easily adopted to probe LM-bonded fuel rods on a commercial scale.

\section{II.B.4 Ultrasonic Testing}

Ultrasonic testing (UT) has not been tried; purchase of a UT machine for this onetime purpose is not feasible, nor is shipping a complete liquid-metal-bonded fuel rod to an installation with one.

\section{CALCULATIONS}

\section{III.A. Increased Fuel Enrichment}

The cold pellet-cladding gap size for an LM bonded fuel rod needed to avoid pellet-cladding mechanical interaction (PCMI) up to $60 \mathrm{MWd} / \mathrm{kgU}$ is larger than that in the conventional design. Since the cladding ID is constrained, the pellet size has to be reduced. Consequently, the enrichment needs to be increased to maintain the same LHR. For constant LHR,

$$
\mathrm{qR}_{\mathrm{F}}^{2}=\text { constant }
$$

where $\mathrm{q}$ is fuel enrichment and $\mathrm{R}_{\mathrm{F}}$ is the fuel radius. Comparing He- and LM-bonded rods:

$$
\frac{q_{L M}}{q_{H e}}=\left(\frac{R_{F}^{H e}}{R_{F}^{L M}}\right)^{2}=\left(\frac{R_{i}-t_{\text {gep }}^{H e}}{R_{i}-t_{\text {gap }}^{L M}}\right)^{2}
$$

where $R_{i}$ is the cladding inner radius and $t_{g a p}$ is the gap thickness. 
Since $\mathrm{t}_{\text {gap }}<<\mathrm{R}_{\mathrm{i}}$,

$$
\frac{\mathrm{q}_{\mathrm{LM}}}{\mathrm{q}_{\mathrm{He}}}=1+2 \frac{\mathrm{t}_{\text {gap }}^{\mathrm{LM}}-\mathrm{t}_{\text {gap }}^{\mathrm{LM}}}{\mathrm{R}_{\mathrm{i}}}
$$

For a typical case, $t_{\text {gap }}^{\mathrm{He}}=80 \mu \mathrm{m}, t_{\text {gap }}^{L M}=150 \mu m$, and $\mathrm{R}_{\mathrm{i}}=0.5 \mathrm{~cm}$. Substituting in the above equation: $\mathrm{q}_{\mathrm{LM}}=1.028 \mathrm{q}_{\mathrm{He}}$. Or, if $\mathrm{q}_{\mathrm{He}}=5 \%$, then $\mathrm{q}_{\mathrm{LM}}=5.14 \%$. This increases the enrichment costs.

\section{III.B. Determination of Local Hot-Spots}

Since voids are essentially small vacuum regions, their presence in the gap causes hot spots in the adjacent fuel due to hindered local heat transfer. Air bubbles have a similar, but less severe, effect. Fuel hot spots caused by voids of different sizes in the LM bond were studied using the HEATING 7.3 heat transfer code [5]. The computations assumed a fuel rod with a cladding inner surface temperature of $334{ }^{\circ} \mathrm{C}$. Heat transfer by radiation across the void portion of the gap was ignored (due to the difficulties of incorporating radiative heat transfer into HEATING 7.3). Fission energy deposition was assumed to be radially uniform. The linear heating rate (LHR) was uniform axially at 270 $\mathrm{W} / \mathrm{cm}$. The pellet diameter was $1.05 \mathrm{~cm}$. Oxides on the cladding ID and surface roughness were ignored. The thermal conductivity of the pellet was assumed to be of the form:

$$
k_{\text {fuel }}=\frac{1}{a+b T}
$$

where $\mathrm{a}=0.004 \mathrm{~m}-\mathrm{K} / \mathrm{W}, \mathrm{b}=2.25 \times 10^{-4} \mathrm{~m} / \mathrm{W}$, and $\mathrm{T}$ is in Kelvin ${ }^{6}$.

A single rectangular void with a height of $1 \mathrm{~cm}$ and a width corresponding to a variable fraction of the pellet periphery was placed in the LM bond. Figure 22 shows the maximum fuel temperature as a function of void fraction (i.e., the fraction of the pellet circumference not covered by LM). The maximum fuel temperature no longer occurs at the fuel center, but moves towards the voided region. For a void fraction of $35 \%$, the hotspot temperature equals that of the complete He-bonded case. Thereafter, the thermal benefit of the LM bond is lost (at least locally). However, if the LM bond is

\footnotetext{
${ }^{6}$ These values are obtained from major nuclear fuel manufacturers. The figures used here represent the average.
} 
circumferentially and axially intact, the reduction in the maximum fuel temperature is $\sim 400{ }^{\circ} \mathrm{C}$.

\section{III.C. Fission Gas Release}

Fuel temperatures of liquid-metal-bonded rods are substantially lower than those in fuel of He-bonded rods when the gap is open; when the gap vanishes, the temperatures in the two cases equalize. Fission gas release begins when the grain faces of the polycrystalline $\mathrm{UO}_{2}$ become saturated with gas that has accumulated at grain boundaries by lattice diffusion from the grain interior. Since diffusion of fission gas depends strongly upon temperature, a lower fuel temperature before gap closure increases the incubation time to release. A modified Booth sphere model, with re-solution taken into account, was adopted. The quantity of fission gas collected at the grain boundary was calculated using realistic time-temperature histories taken from a recent NRC review [6]. The saturation coverage of gas at the grain boundary proposed by Dowling was adopted [7]. Two timedependent diffusivities of Xe atoms in $\mathrm{UO}_{2}$ lattice, $\mathrm{D}_{\text {high }}$ [8] and $\mathrm{D}_{\text {low }}$ [9], were studied. At $1400{ }^{\circ} \mathrm{C}, \mathrm{D}_{\text {high }}$ is $\sim 20$ times $\mathrm{D}_{\text {low }}$. Two locations in the fuel pellet were chosen: the pellet centerline and midway to the crack tip ( $\mathrm{r} / \mathrm{R} \approx 0.34)$. Ref. 4 has a complete discussion of this topic. Figure 23 shows that the differences between time-to-saturation with LM and He in the gap are as high as 1 year, and as low as 1-2 days.

\section{III.D. Avoidance of PCMI in Reactivity Insertion Accident (RIA)}

An RIA happens when there is an accidental rapid increase in the reactivity in the core, typically by 100 fold. Typically, this is caused by an inadvertent control rod ejection. The time range of the accident is around 10 milliseconds before the original reactivity level is restored.

The rapid energy generated in the fuel causes the fuel to expand. It is of interest to know the BOL gap thickness that just initiates PCMI during an RIA following normal operation to $\sim 60 \mathrm{MWd} / \mathrm{kgU}$. This gap dimension guarantees no cladding stress due to pellet expansion.

To approach this problem, the FRAPCON 3.2 and FRAPTRAN 1.2 fuel rod behavior codes were utilized. Appropriate modifications to the temperature calculation 
subroutines of the codes were needed to account for the 100-fold in gap conductance resulting from replacing He by LM. Other material effects, such as the vapor pressure of LM, slight thinning of cladding with time due to LM and fission gas release, were beyond the scope of the present study.

For both gap fillers, the temperature drop across the gap (open or closed) is calculated from the formula:

$$
\Delta T_{\text {gap }}=\frac{q(z)}{h}
$$

where

- $\Delta T_{\text {gap }}$ is the temperature drop across the gap

- $q(z)$ is the heat flux at elevation $\mathrm{z}$

- $\mathrm{h}=\mathrm{k}_{\mathrm{LM}} / \delta$ is the conductance of the gap.

- $\mathrm{k}_{\mathrm{LM}}$ is the thermal conductivity of the $\mathrm{LM}=30 \mathrm{~W} / \mathrm{m}-\mathrm{K}$

- $\delta$ is the gap width

Appropriate source codes were modified and new executable files were compiled. Input files for test cases were obtained from PNNL. Figure 24 compares the fuel surface temperatures computed from the original FRAPTRAN and the code modified for LM in the gap. This case is for a typical 10 ms RIA under hot zero power condition (HZP) for a full-length PWR 17x17 at $60 \mathrm{MWd} / \mathrm{kgM}$. It can be seen that replacing He with LM in the gap reduces the peak fuel surface temperature by $400{ }^{\circ} \mathrm{C}$. With LM in the gap, the fuel surface temperature is essentially the same as the cladding inside temperature.

The matching input required by both codes is proprietary information, so new input codes will be constructed using information from Ref 6 . 


\section{APLICATION OF THE LM BOND TO OTHER FUELS}

The LM-bonded gap has been chosen for a NERI project [10] that is investigating replacement of $\mathrm{UO}_{2}$ fuel in LWRs by $(\mathrm{U}, \mathrm{Zr}) \mathrm{H}_{1.6}$. The thermal conductivity of the hydride fuel is $~ 5$ - 8 times larger than that of $\mathrm{UO}_{2}$. As a result, in helium-filled hydride fuel elements, the largest temperature drop is across the gap. Replacement of the He bond by an LM bond eliminates this thermal resistance, with a correspondingly large decrease in the hydride fuel centerline temperature.

The supercritical water reactor concept [11] may also require a liquid metal bond in order to maintain acceptably low fuel temperatures prior to gap closure (and even to avoid PCMI entirely).

\section{CONCLUSIONS}

Replacement if helium in the fuel-cladding gap with a low-melting alloy if $\mathrm{Pb}, \mathrm{Sn}$ and $\mathrm{Bi}$ has been thoroughly investigated.

\section{A. Behavior of LM in a fuel rod (small-scale test)}

- The LM shows no chemical affinity with either $\mathrm{UO}_{2}$ fuel or Zry cladding with a thin ( $<10$ micron) oxide lining on the ID.

- Surface treatment does not improve the wetting properties of $\mathrm{LM}$ on $\mathrm{UO}_{2}$ and Zry.

- By loading fuel pellets into evacuated cladding tubes filled with LM and pressurizing to $\sim 7 \mathrm{~atm}$, voids and bubbles are eliminated.

- With an internal rod pressure of $\sim 7 \mathrm{~atm}, \mathrm{LM}$ is pushed into cracks as narrow as 3 microns. This increases the pellet thermal conductivity.

B. LM-bonded full-scale fuel-element fabrication 
- Full-scale industrially-compatible fuel rod fabrication was successfully demonstrated.

- Application of the activated-gold void-detection method indicated that the LM bond in the full-size fuel element was intact.

- Destructive examination of the full-scale fuel rod confirms the integrity of the LM bond.

C. NDE methods for assessing LM bond integrity

- Eddy current testing could not detect voids in the LM bond.

- Use of X-rays to image voids edge-on appears promising.

\section{Analytical studies}

- The LM-bonded fuel rod with a 150-micron cold BOL radial gap that avoids PCMI until $60 \mathrm{MWd} / \mathrm{kgU}$ requires an enrichment of 5.14\%, compared to 5\% for the comparable He-filled fuel element.

- Use of the HEATING 7.3 code indicates that the maximum fuel temperature no longer occurs at the fuel center, but moves towards the voided region. For a void fraction of $35 \%$, the hot-spot temperature equals that of the complete He-bonded case.

- LM bonding initially reduces the centerline fuel temperature by $\sim 400{ }^{\circ} \mathrm{C}$ for an LHR of $270 \mathrm{~W} / \mathrm{cm}$.

- Differences between the time of the onset of fission-gas release with LM and He in the gap are as high as $\sim 1$ year, and as low as 1-2 days.

- Applications of the FRAPCON and FRAPTRAN codes with He replaced by LM in the gap showed a $600{ }^{\circ} \mathrm{C}$ reduction of the peak fuel temperature in a typical RIA. 


\section{ACKNOWLEDGMENTS}

We are truly thankful for the generous help from the following individuals:

- R. Montgomery of the ANATECH Co. for running the FALCON fuel behavior code.

- Dr. Harold Scott in providing us with realistic temperature data for assessing the performance of LM-bonded fuel rods.

- Dr. Kenneth Childs in running the HEATING 7.3 code.

- Mr. Michael Hadland at X-Tek System Ltds in England for the X-ray testing of the dummy fuel rod.

- Kenneth Geelhood at PNNL for his advice on how to modify the FRAPCON and FRAPTRAN codes for RIA calculations of LM-bonded fuel rods.

- Unknown reviewers for their favorable comments of our NEER proposal that resulted in the award that supported this work.

- The U.S. taxpayer whose taxes were the ultimate source of the money that made this study possible.

\section{REFERENCES}

1. R. F. WRIGHT, G. J. SCHOESSOW, J. S. TULENKO, T. ADAMS, and R. G. CONNELL, Jr., Proc. Int. Topical. Mtg. Light Water Reactor Fuel Performance, West Palm Beach, Florida, April 17-21, 1994, p. 659, American Nuclear Society (1994).

2. R. F. WRIGHT, J. S. TULENKO, G. J. SCHOESSOW, R. CONNELL, M. A. DUBECKY, and T. ADAMS, Nucl. Technol., 115 (1996) 281-292.

3. D. OLANDER, Y. KIM, and S. YAGNIK, Nucl. Technol., 128 (1999) 300.

4. D. WONGSAWAENG and D. OLANDER, "Effect of Replacing Helium With a Liquid Metal in the Fuel-Cladding Gap on Fission Gas Release,” Nucl. Technol., 146 (2004) 211.

5. K. W. CHILDS, “HEATING 7.2 User's Manual,” ORNL/TM-12262 (February 1993; update to Chapter 4, February 1997). 
6. G. O’DONNELL, H. SCOTT, and O. MEYER, “A New Comparative Analysis of LWR Fuel Designs,” NUREG-1754, December 2001.

7. D. DOWLING, R. WHITE, and M. TUCKER, J. Nucl. Mat., 110 (1982) 37

8. Hj MATZKE, J. Chem. Soc, Farad. Trans, 86 (1990) 1.

9. D. DAVIES, G. LONG, AERE Report 4347, Atomic Energy Research Establishment, Harwell (1963).

10. E. GREENSPAN, H. GARKISCH, J. MALEN, M. MOALEM, D. OLANDER, B. PETROVIC, Z. SHAYER, and N. TODREAS, “Preliminary Assessment of Possibilities for Improving the Performance of LWRs Using Hydride Fuel,” Trans. Amer. Nucl. Soc., 89 (2003) 381-382.

11. J. BUONGIORNO, “An Alternative SCWR Design Based on Vertical Power Channels and Hexagonal Fuel Assemblies,” Global 2003 Mtg., New Orleans, Louisiana, November 16-20, 2003, p. 1155-1162.

\section{PRESENTATIONS}

- 2004 ANS Winter Meeting, Washington, D.C., Nov. 14-18, 2004, American Nuclear Society.

- 2004 International Meeting on LWR Fuel Performance, Orlando, Florida, Sep. 19-22, 2004, American Nuclear Society.

- GLOBAL'03, New Orleans, Louisiana, Nov. 16-20, 2003, American Nuclear Society. 
Table 1 Contact angle measurement of the liquid metal on various materials and different surfaces preparation methods $\left(130{ }^{\circ} \mathrm{C}\right)$

\begin{tabular}{|c|c|c|c|c|}
\hline \multirow{2}{*}{ Cleaning Method } & \multicolumn{4}{|c|}{ Contact Angle (degrees) } \\
\hline & Pyrex & Quartz & Zircaloy & $\mathbf{U O}_{2}$ \\
\hline Acetone wash & 155 & 156 & 148 & 155 \\
\hline $\begin{array}{l}\text { Glass } \\
\text { - } 50 \% \text { vol. Water } \\
\text { - } 45 \% \text { Nitric acid } \\
\text { - } 5 \% \mathrm{HF} \\
\text { - } 2 \mathrm{~min}\end{array}$ & 142 & 154 & & \\
\hline $\begin{array}{l}\text { Zircaloy etch } \\
\qquad 100 \mathrm{~mL} \text { water } \\
\text { - } 10 \mathrm{~mL} \mathrm{HF} \\
\bullet \quad 20 \mathrm{sec}, 2 \mathrm{~min}\end{array}$ & & & 158,161 & \\
\hline $\begin{array}{l}\mathrm{UO}_{2} \text { etch } \\
\qquad 1 \mathrm{~mL} \text { hydrogen } \\
\text { peroxide } \\
\text { - } 10 \mathrm{~mL} \text { sulfuric } \\
\text { acid } \\
\text { - } 3 \mathrm{~min} \\
\end{array}$ & & & & 160 \\
\hline Sandblasting & 157 & 137 & 129 & \\
\hline
\end{tabular}

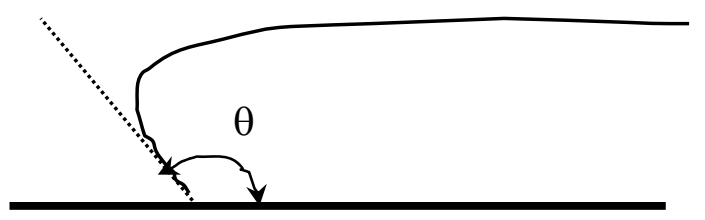

$\theta<90^{\circ}$ : wetting

$\theta>90^{\circ}$ : nonwetting

Figure 1 Definition of the contact angle 


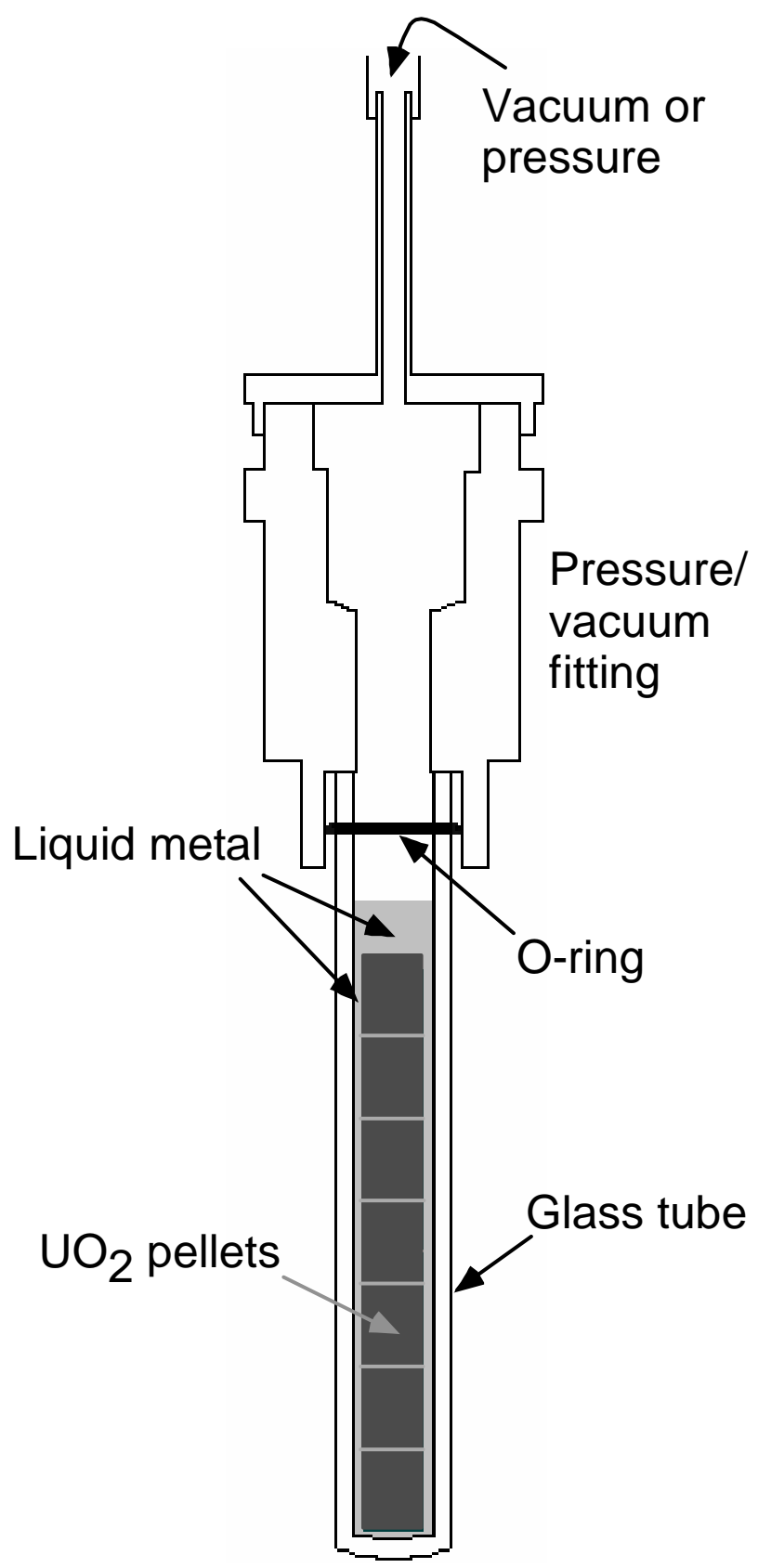

Figure 2 Schematic drawing of the small-scale glass-clad apparatus 


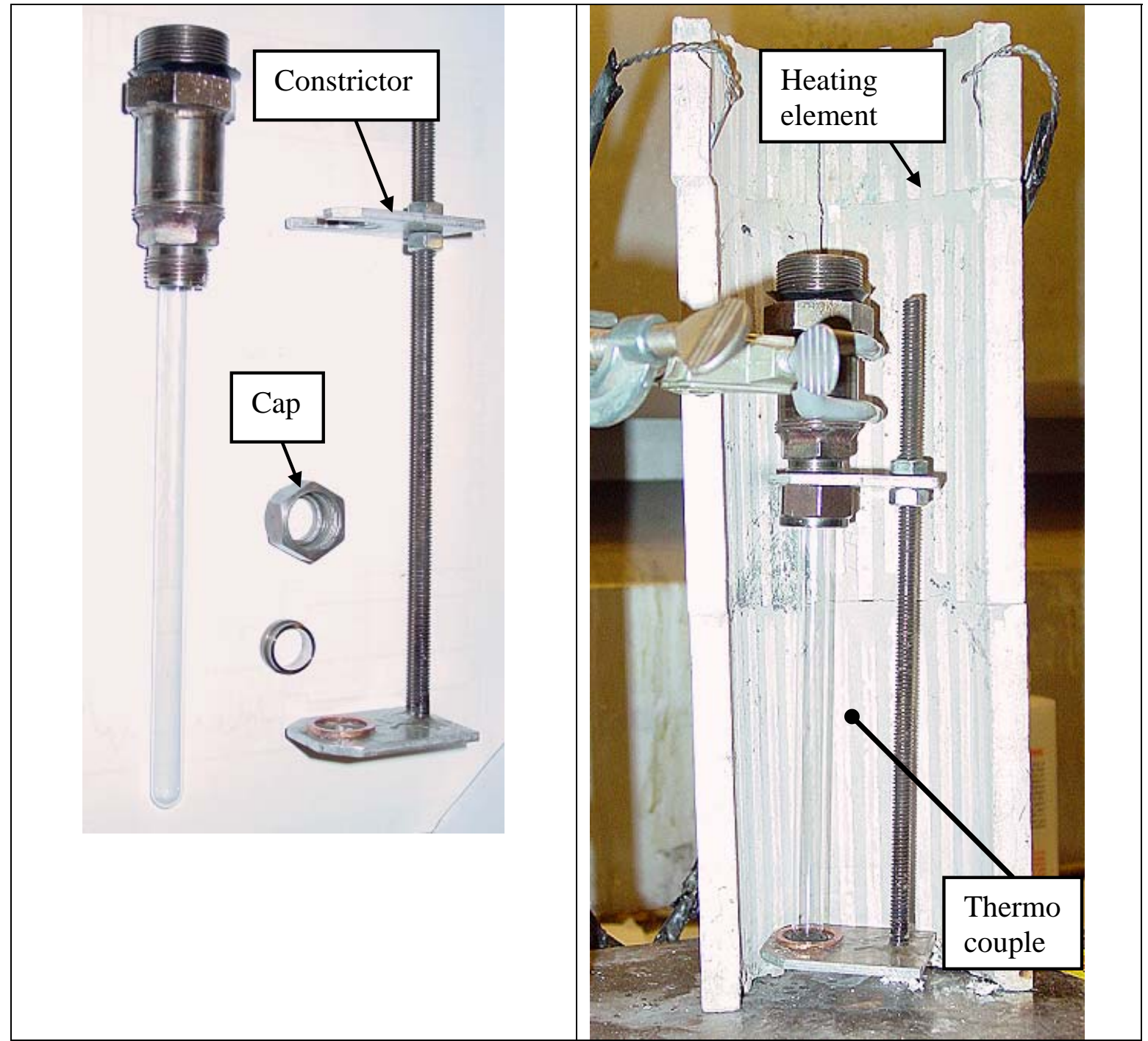

Figure 3a and 3b Pictures of experimental apparatus 


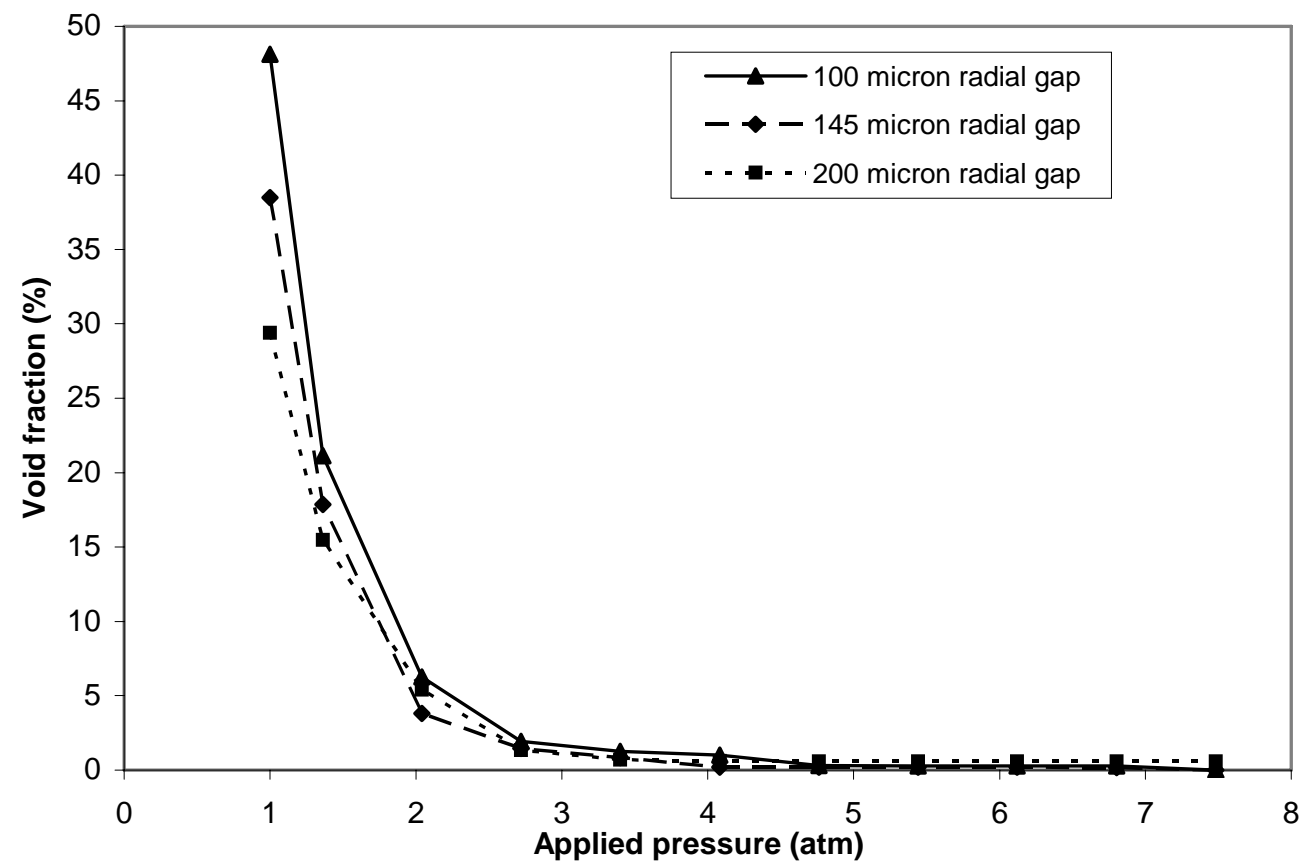

Figure 4 Void fraction vs. applied pressure for 10 dished PWR pellets in glass tubing 


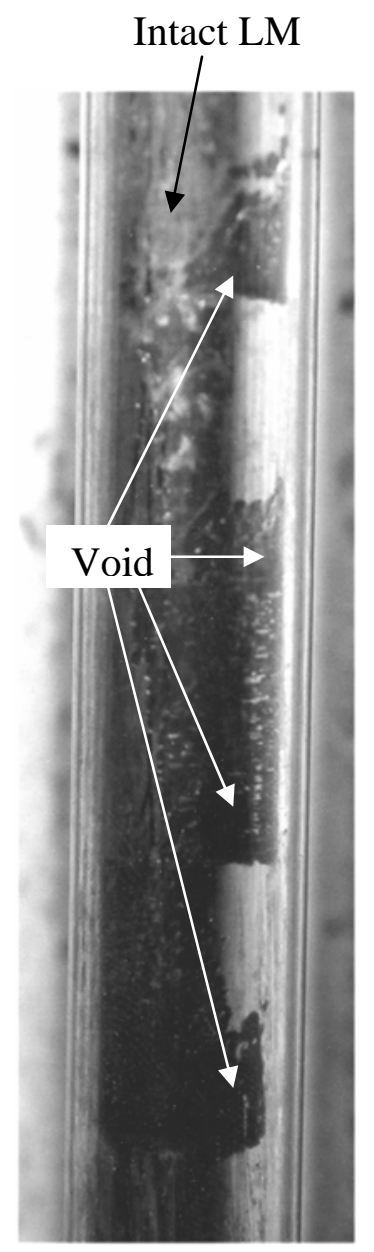

$1.0 \mathrm{~atm}$

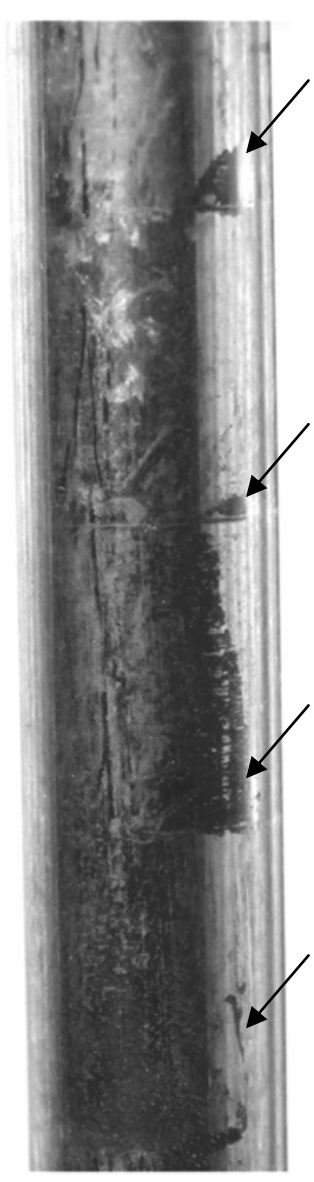

2.7 atm

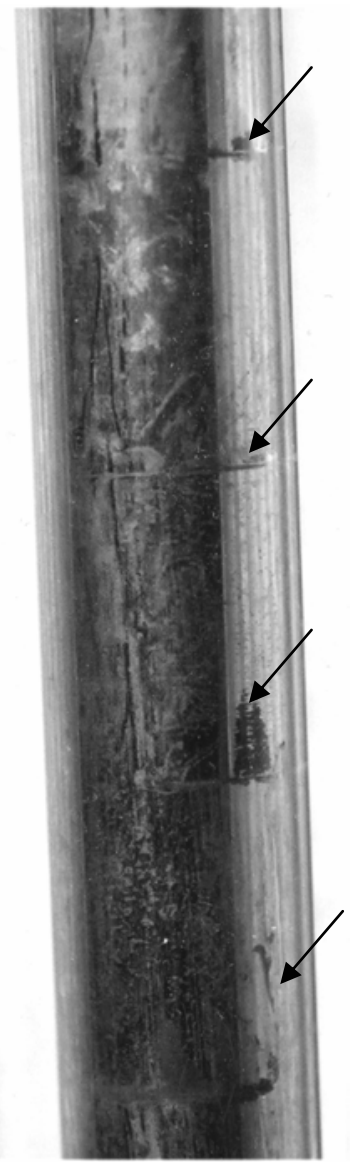

$4.1 \mathrm{~atm}$

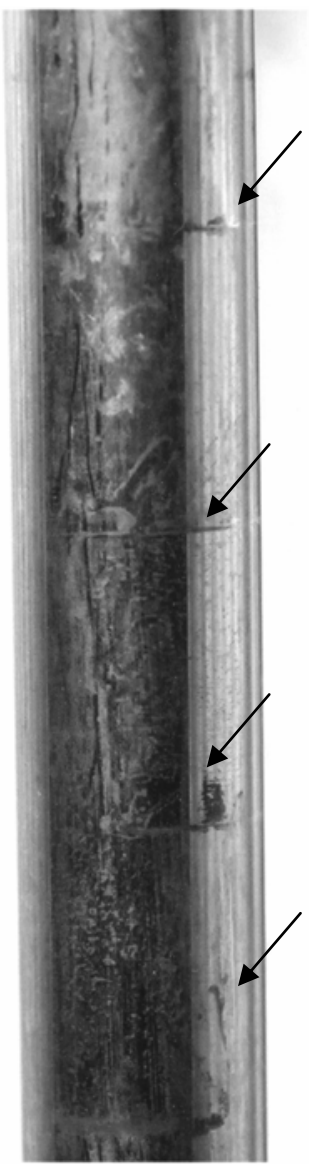

$5.4 \mathrm{~atm}$

Figures 5(a) - 5(d) Collapse of voids in $\mathrm{LM}$ bond at $150{ }^{\circ} \mathrm{C}$ with the application of overpressure 


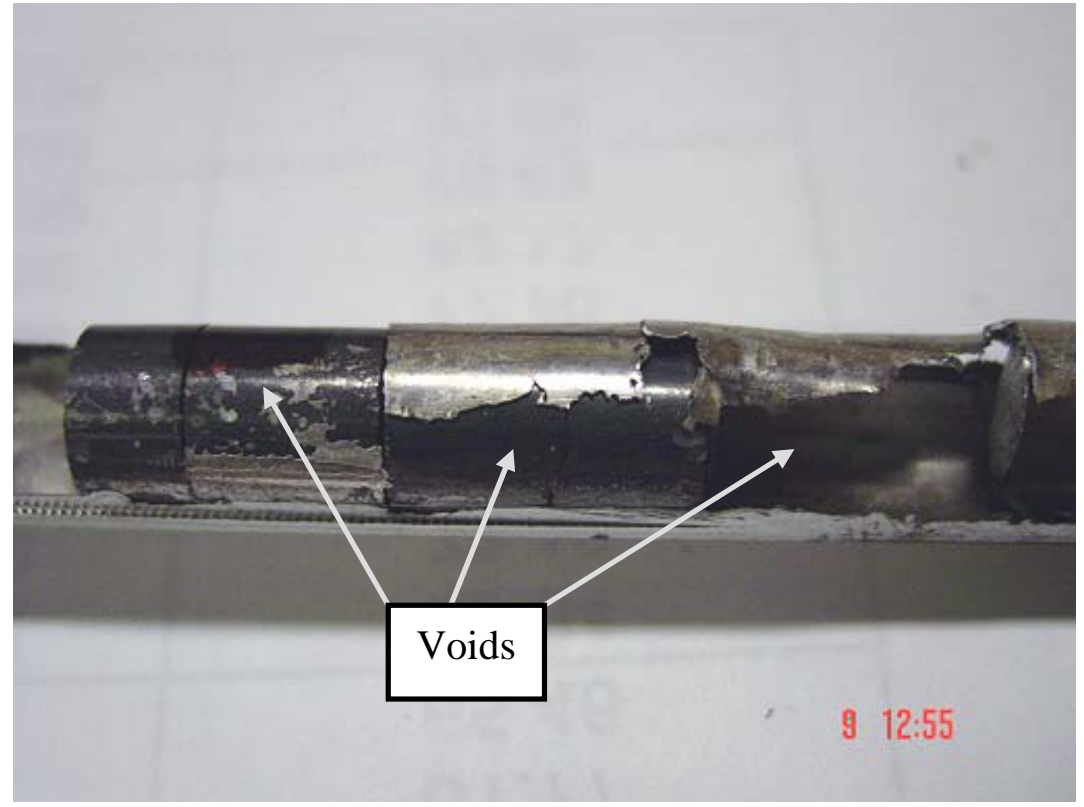

Figure 6 Voids in LM bond of Zry cladding (removed) and stack of flat-end BWR pellets loaded into air-filled tubes

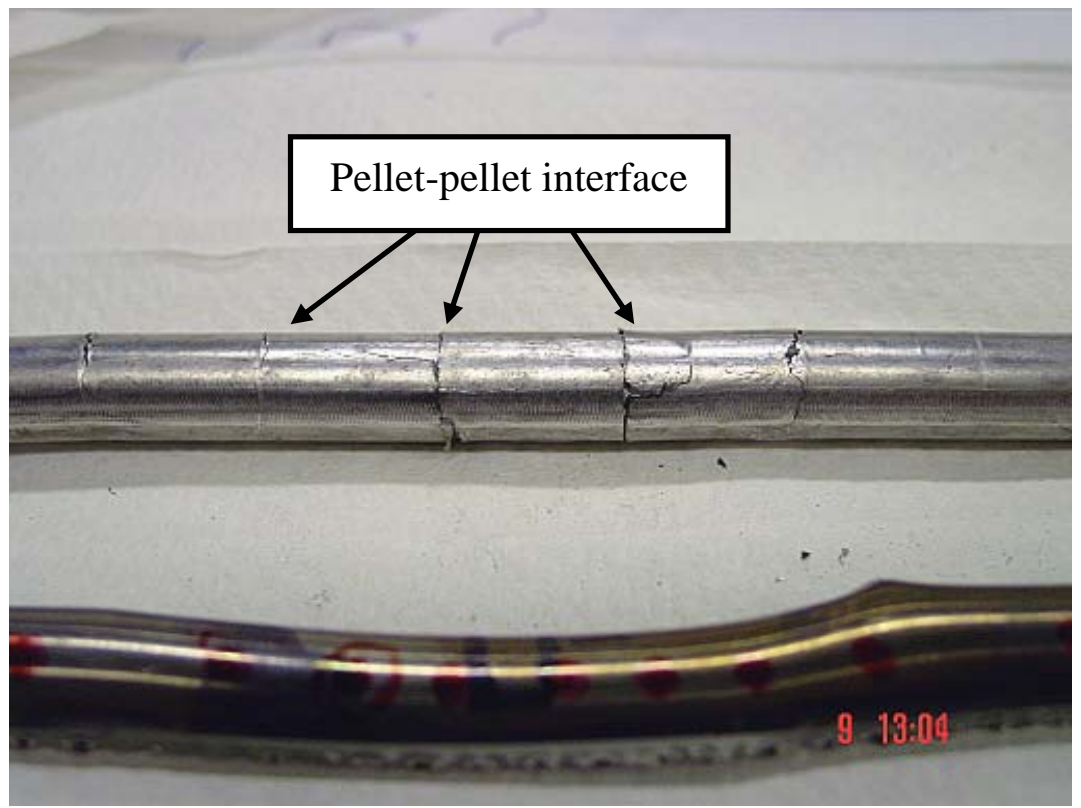

Figure 7 Destructive examination of 10-pellet mini fuel rod with $114 \mu \mathrm{m}$ radial gap 


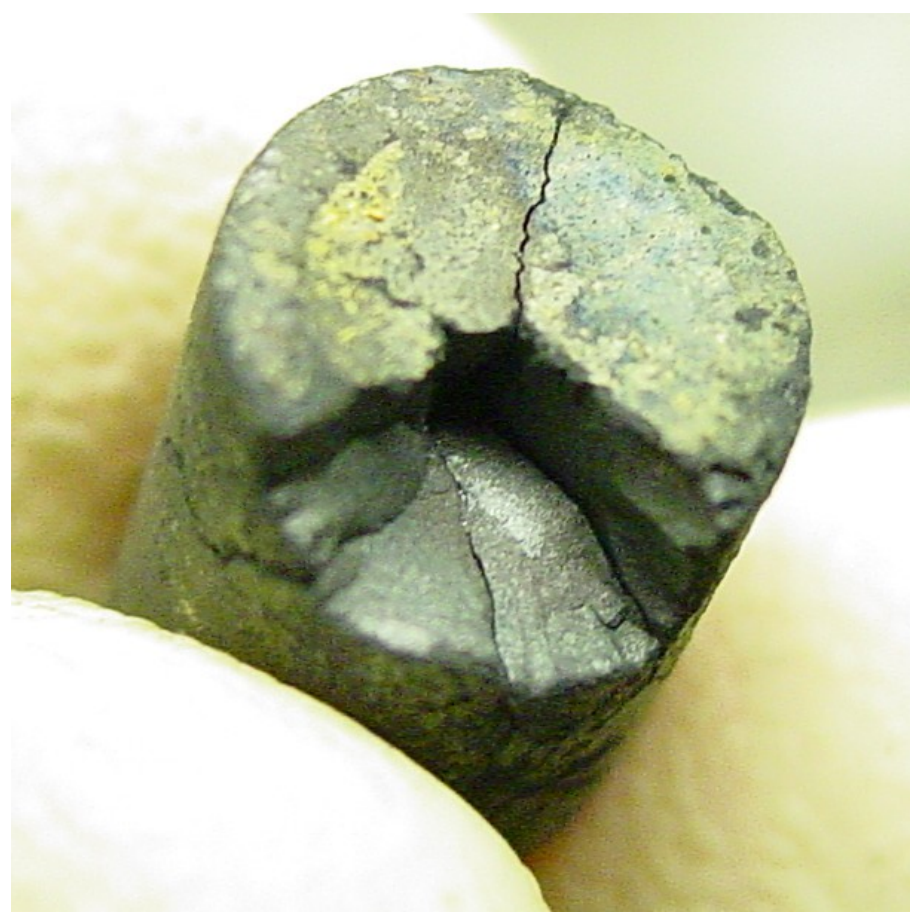

Figure 8 Cracks in pellets heated with an electric heat gun and then thermally quenched 


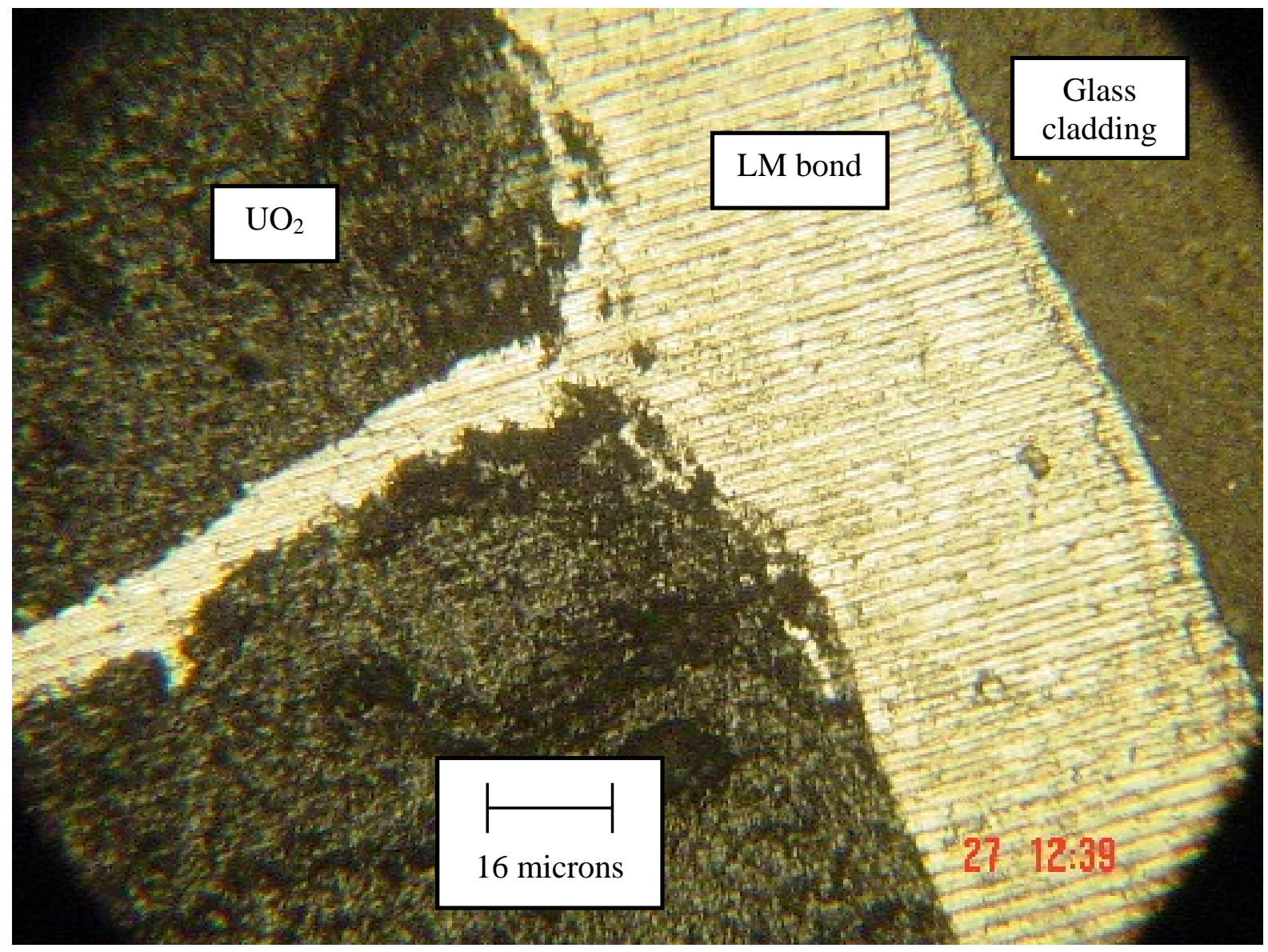

Figure 9 LM in crack in fuel pellet

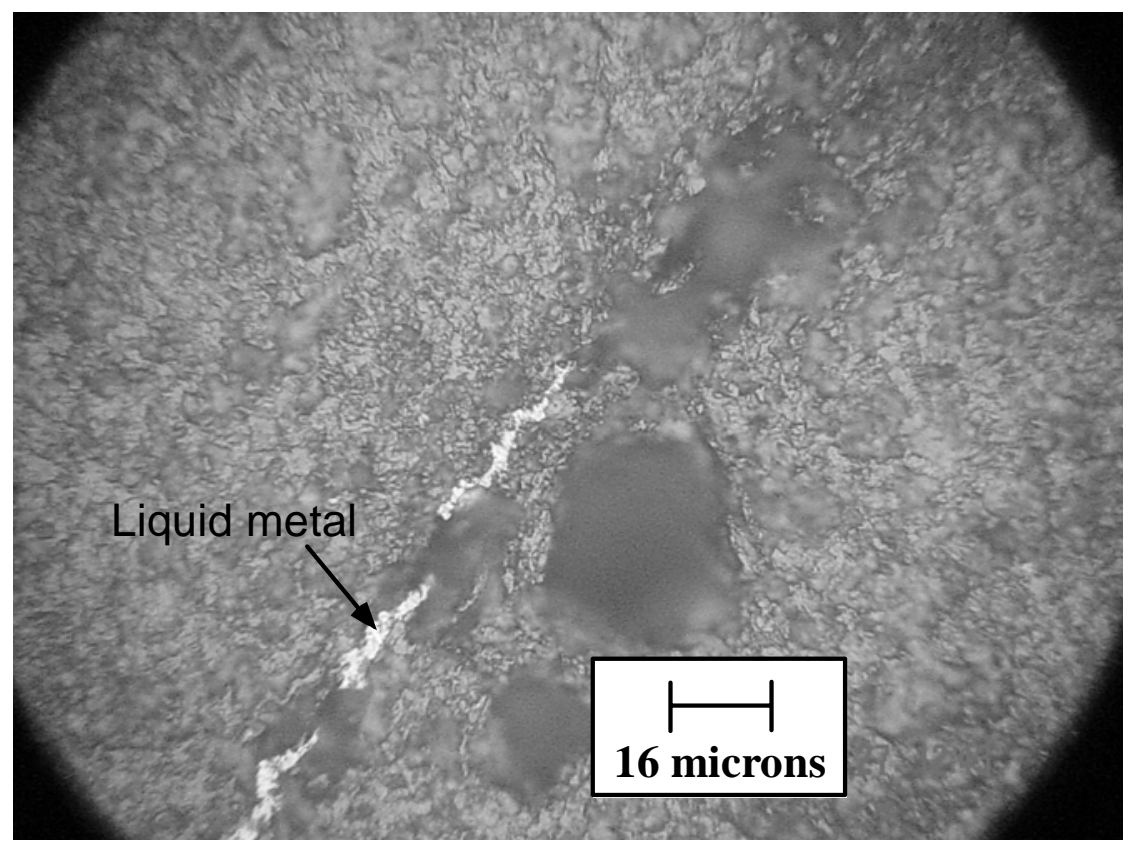

Figure $10 \mathrm{LM}$ in a $3 \mu \mathrm{m}$-wide crack in $\mathrm{UO}_{2}$ 


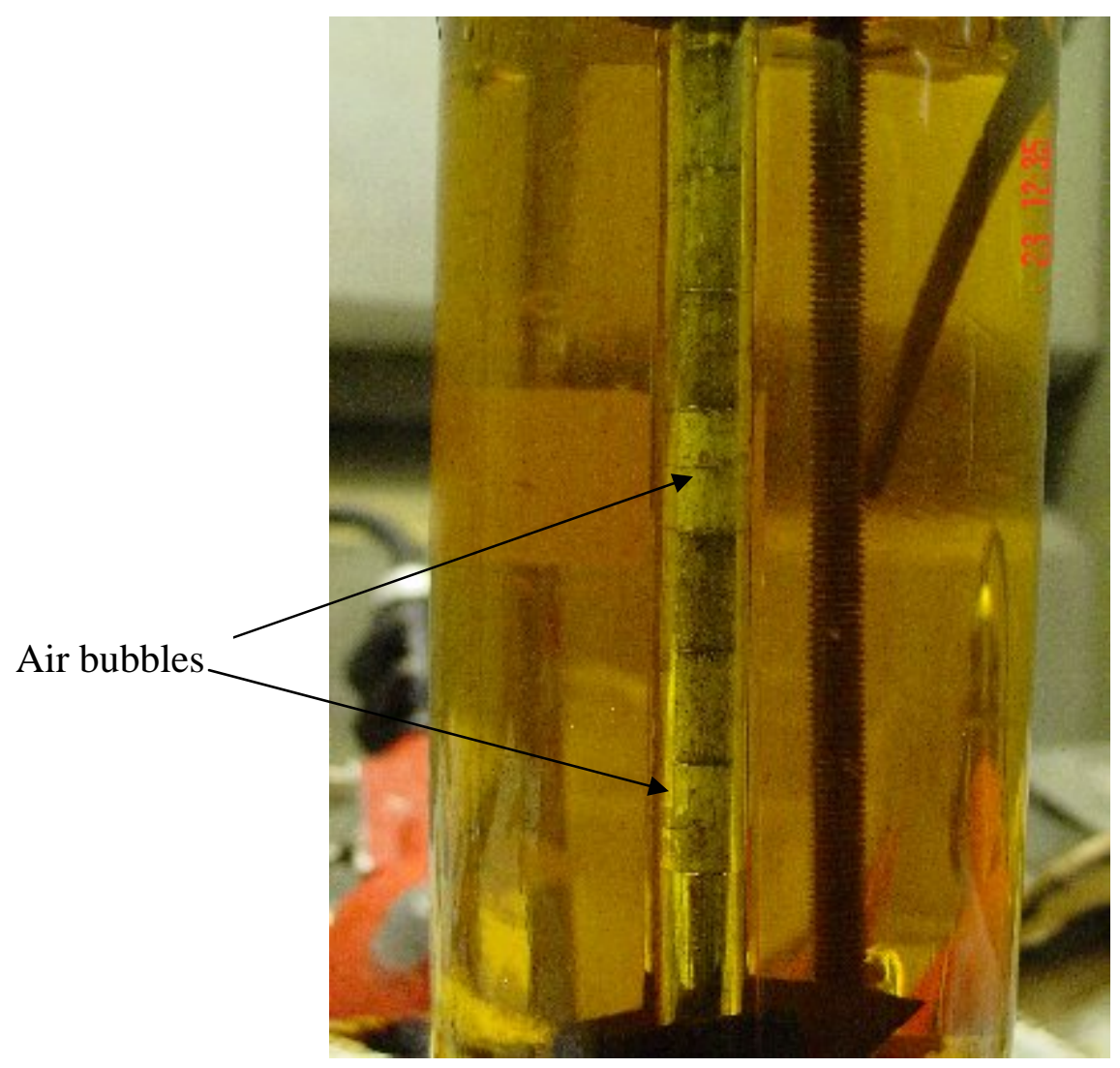

Figure 11 Air bubbles from the porosity in alumina pellets formed in the LM bond after rapid depressurization 


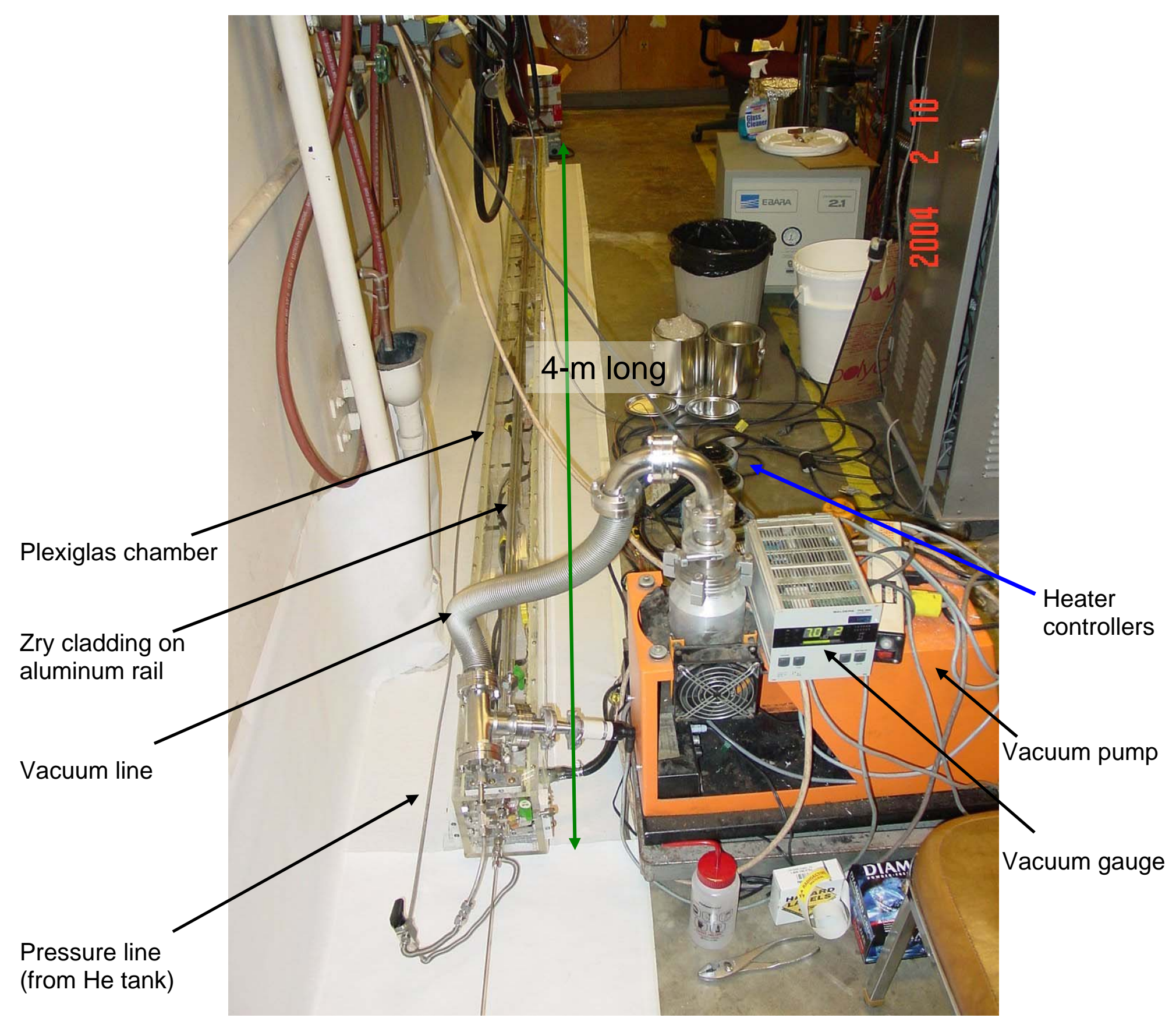

Figure 12 Full-scale fabrication demonstration apparatus 


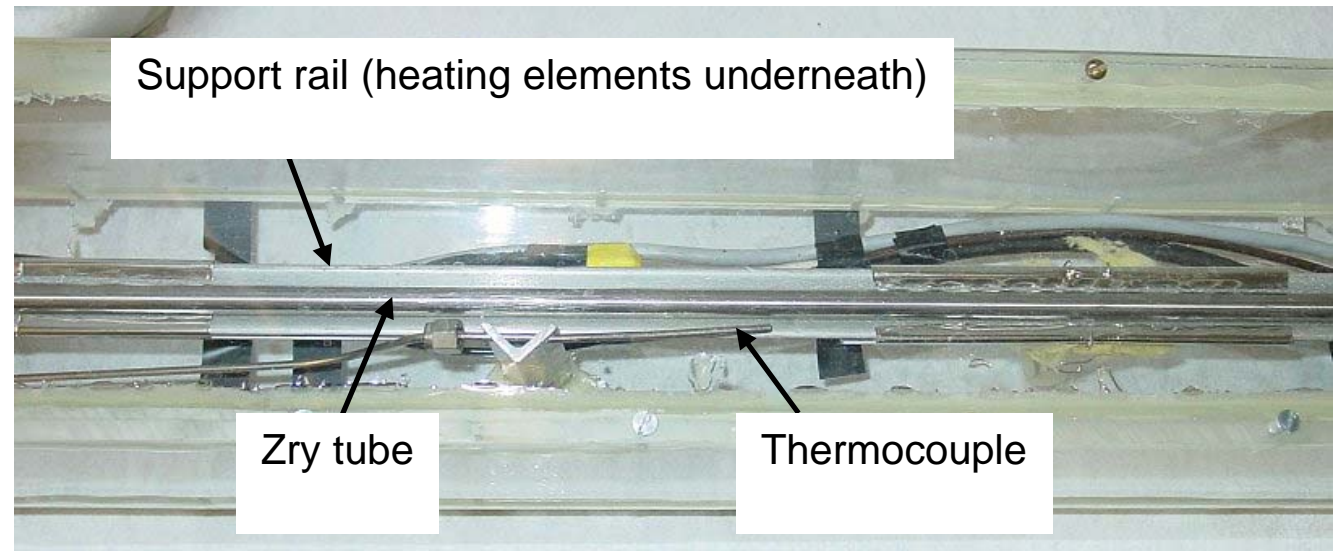

Figure 13 Support rail, Zry tube, and one of six thermocouples

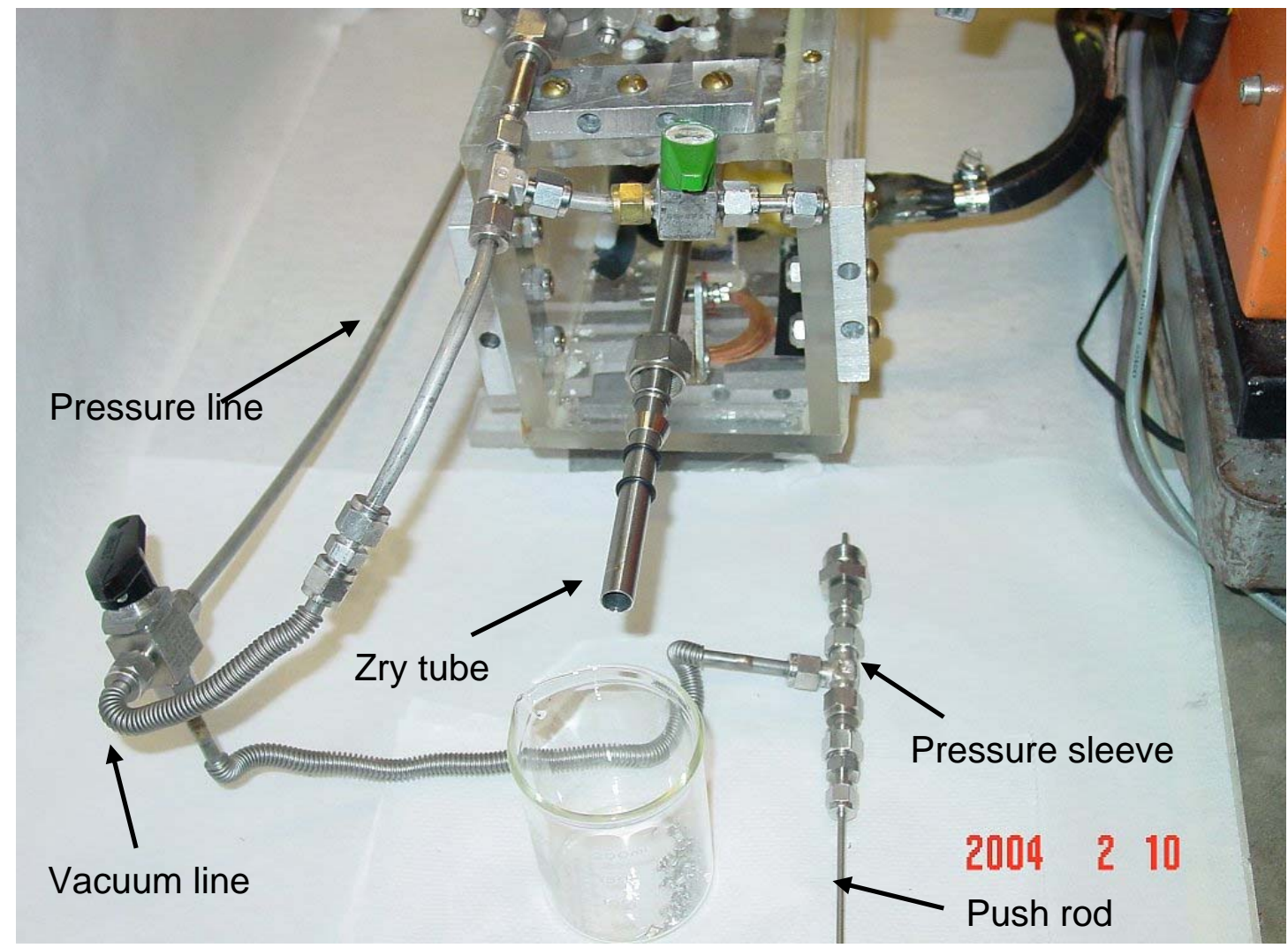

Figure 14 Open end of the apparatus for $\mathrm{LM}$ and $\mathrm{UO}_{2}$ loading 


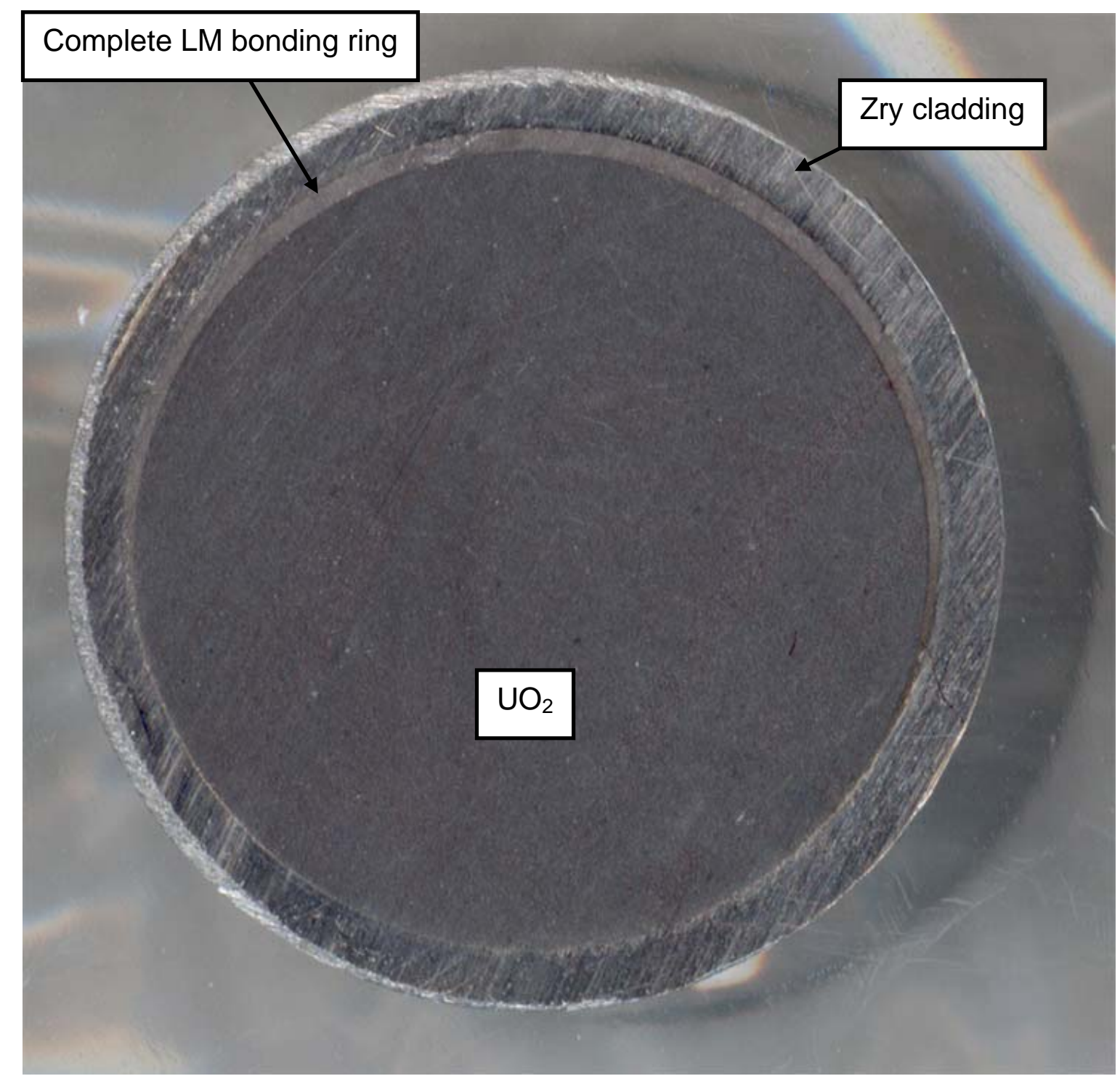

Figure 15 Complete LM bonding in one section of the 4-m full-scale fuel rod 


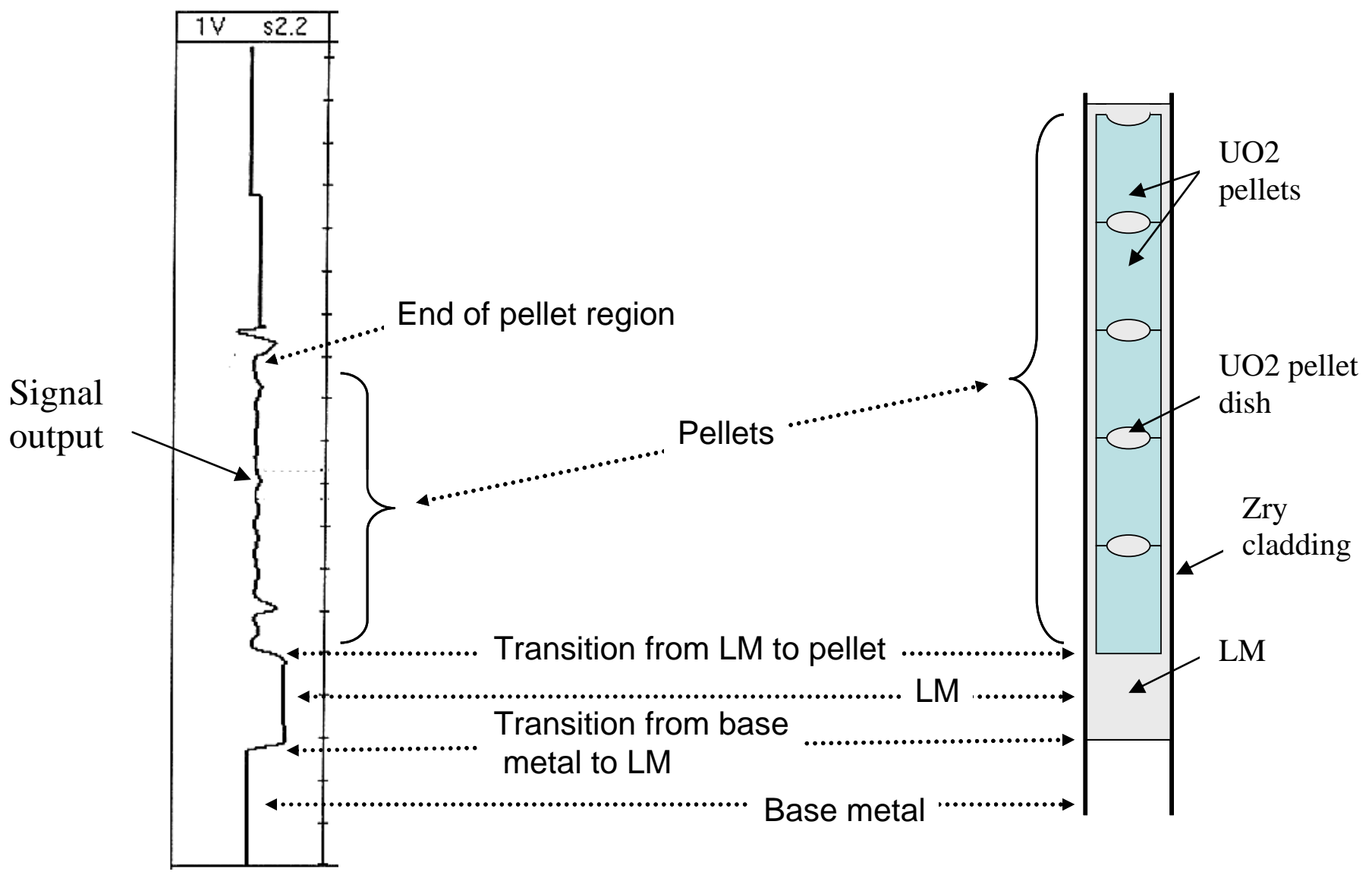

Figures 16 Matching of the encircling probe signal to the specimen with no voids inside 


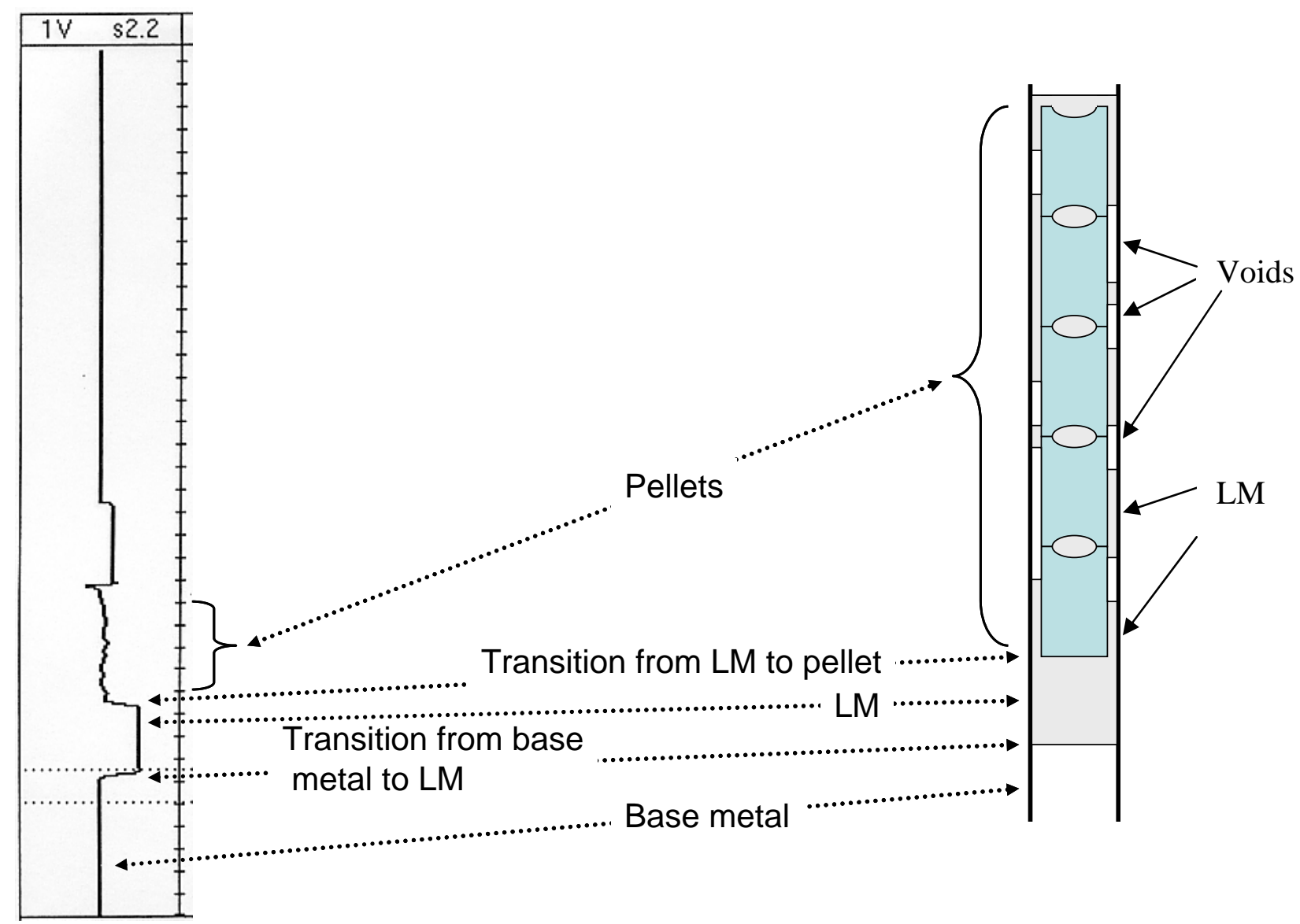

Figures 17 Matching of the encircling probe signal to the specimen containing voids 


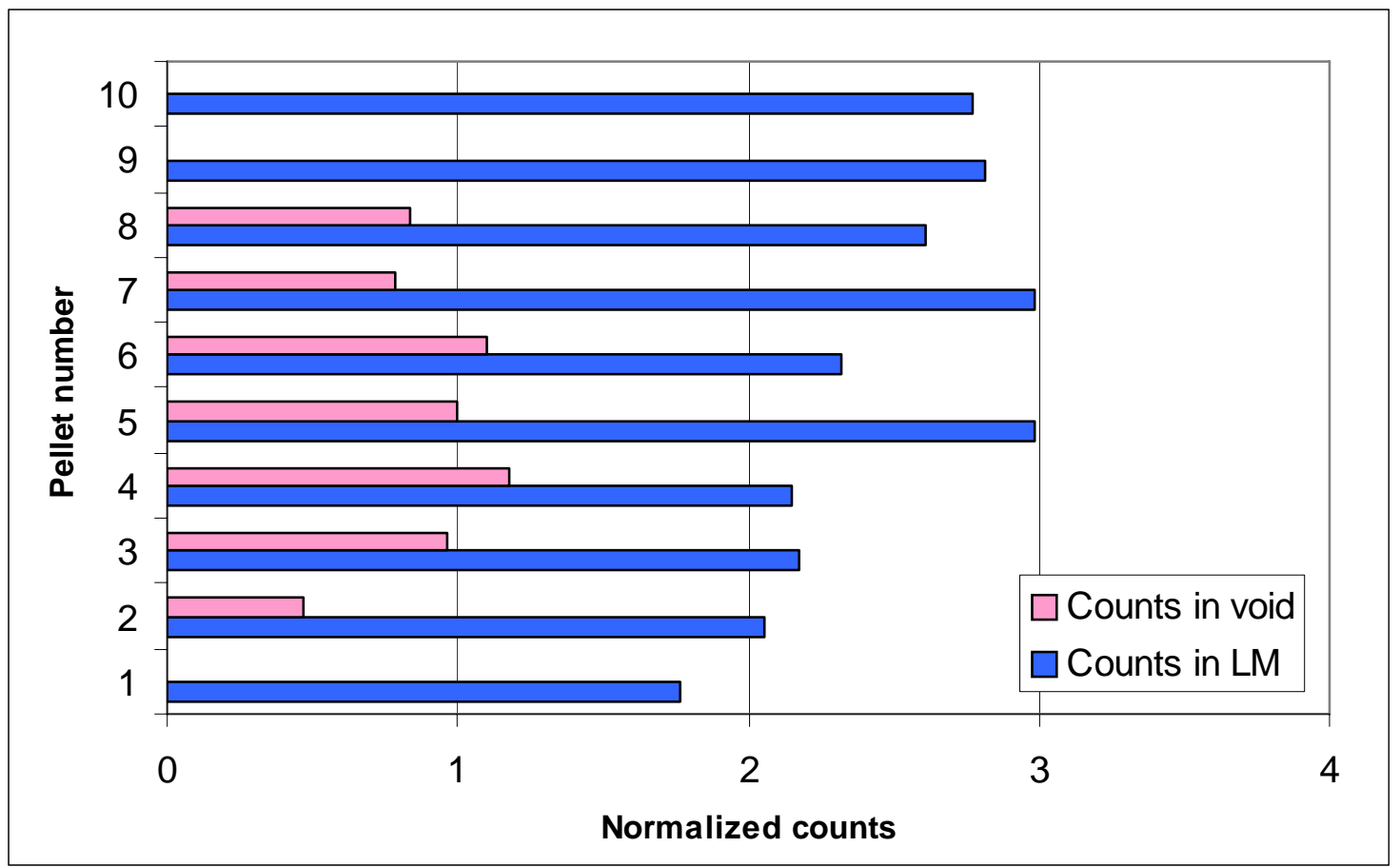

Figure 18 Gamma-ray counts from Au-198 dissolved in the LM bond between a glass-clad, 10-pellet mini fuel rod 


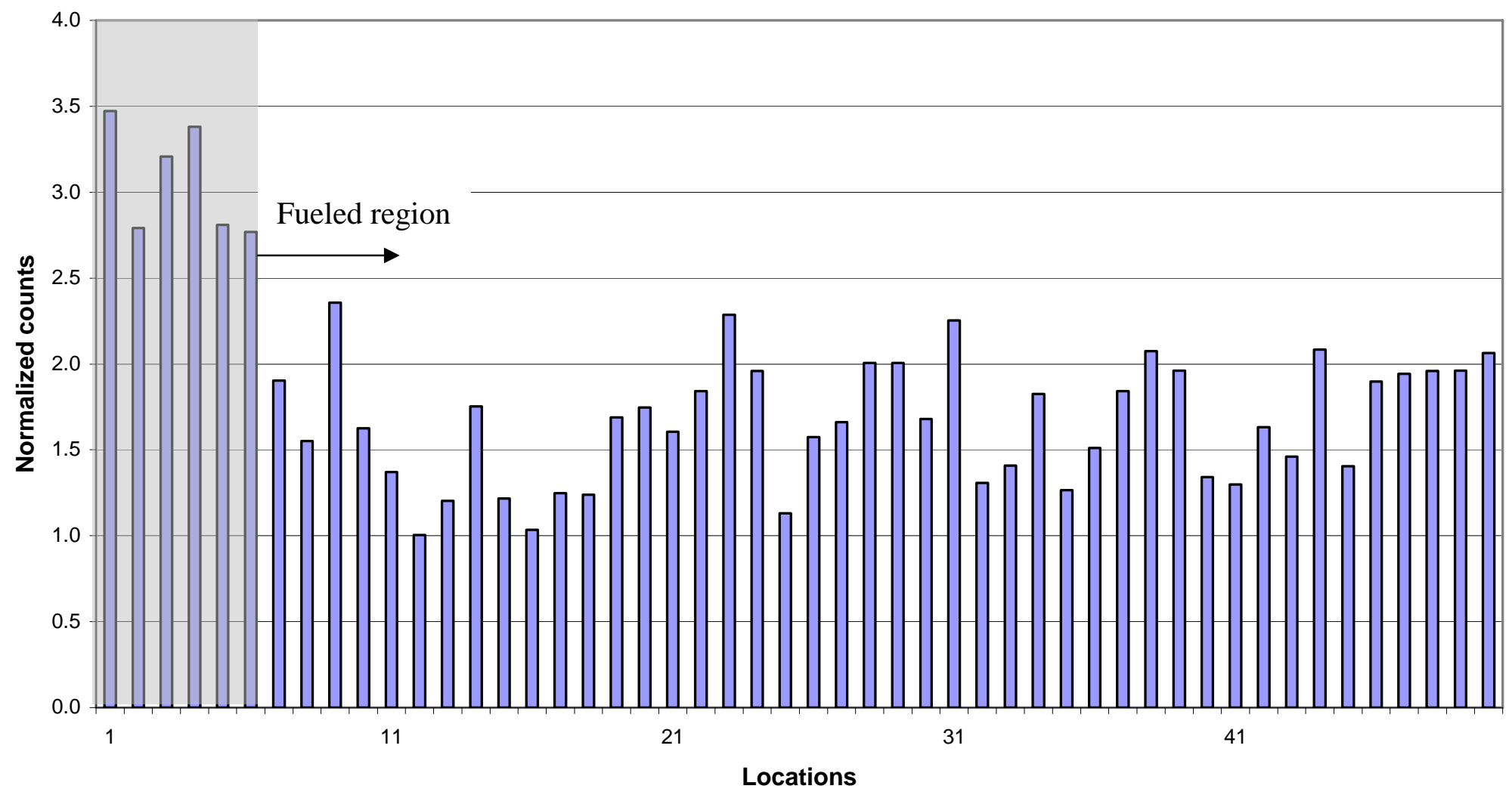

Figure 19 Gold gamma ray counts along the length of the full-scale fuel element 

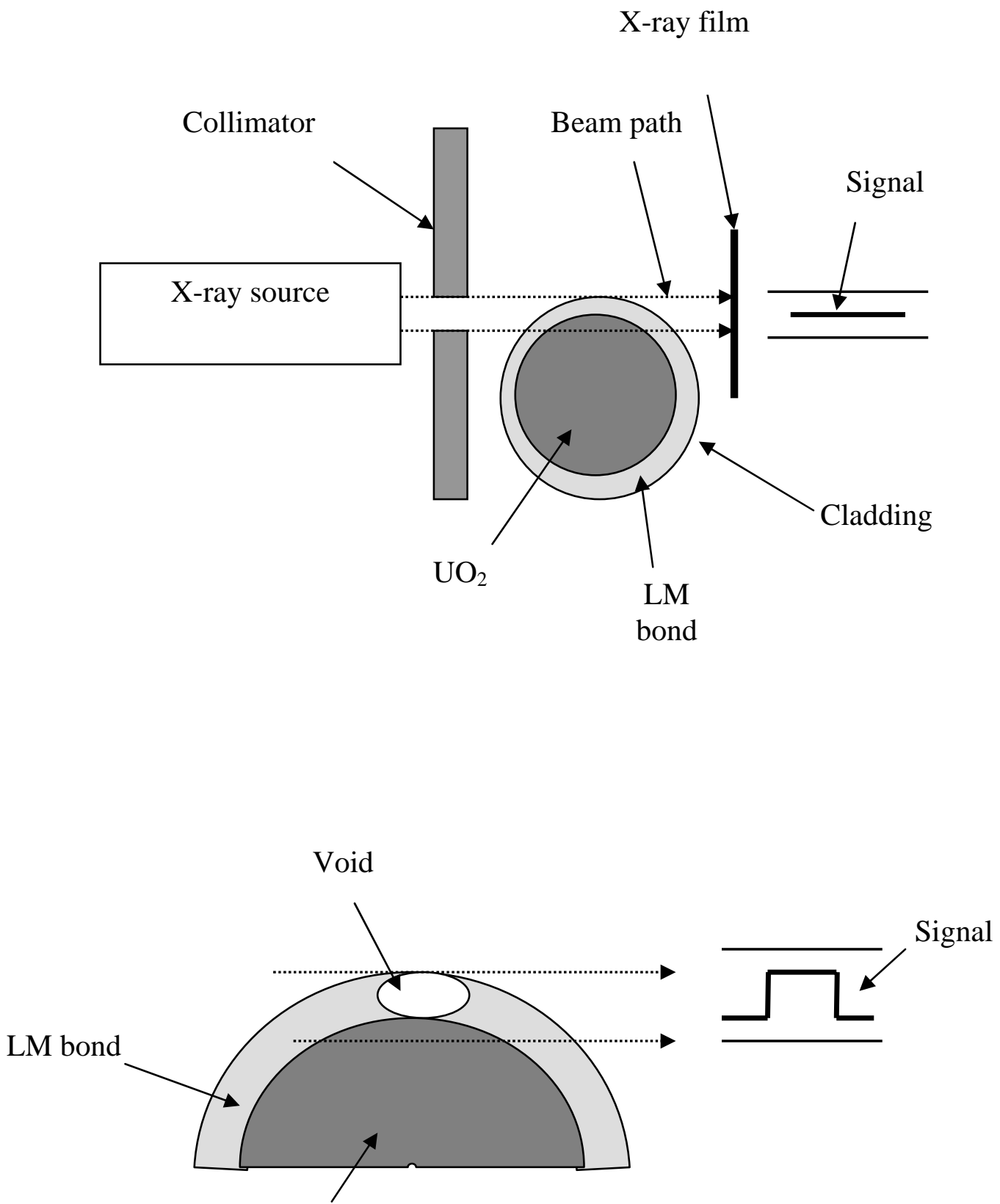

Fuel

Figure 20 Drawing of the X-ray photography apparatus 


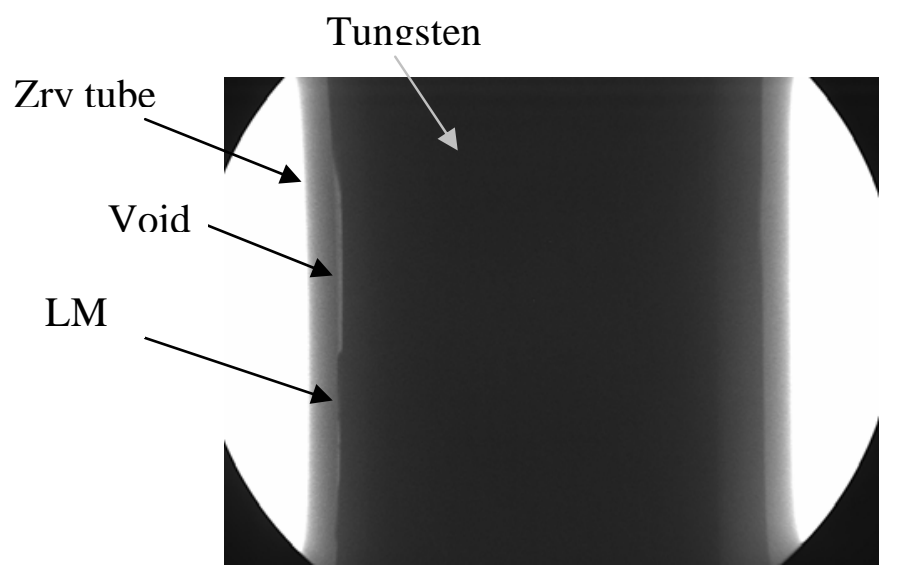

Figure 21(a) X-ray photograph of the dummy fuel rod. Voids are clearly seen as white region in the gap

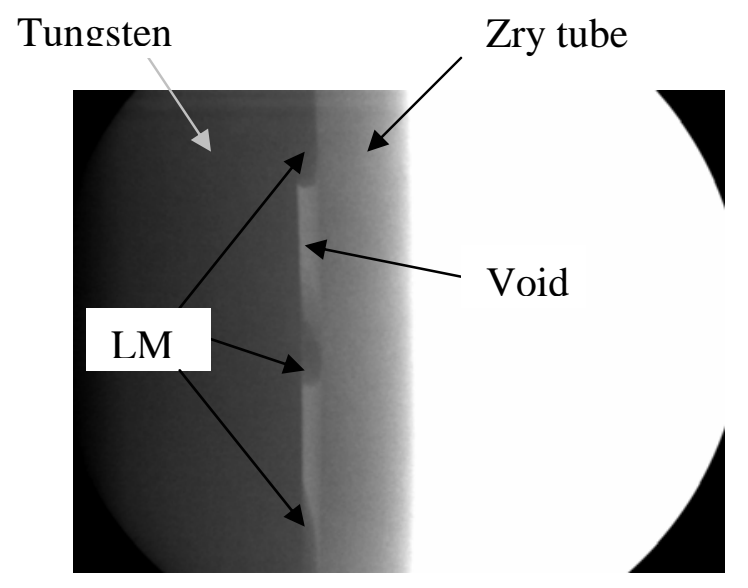

Figure 21(b) Higher magnification X-ray photograph of the dummy fuel rod showing details of the void region 


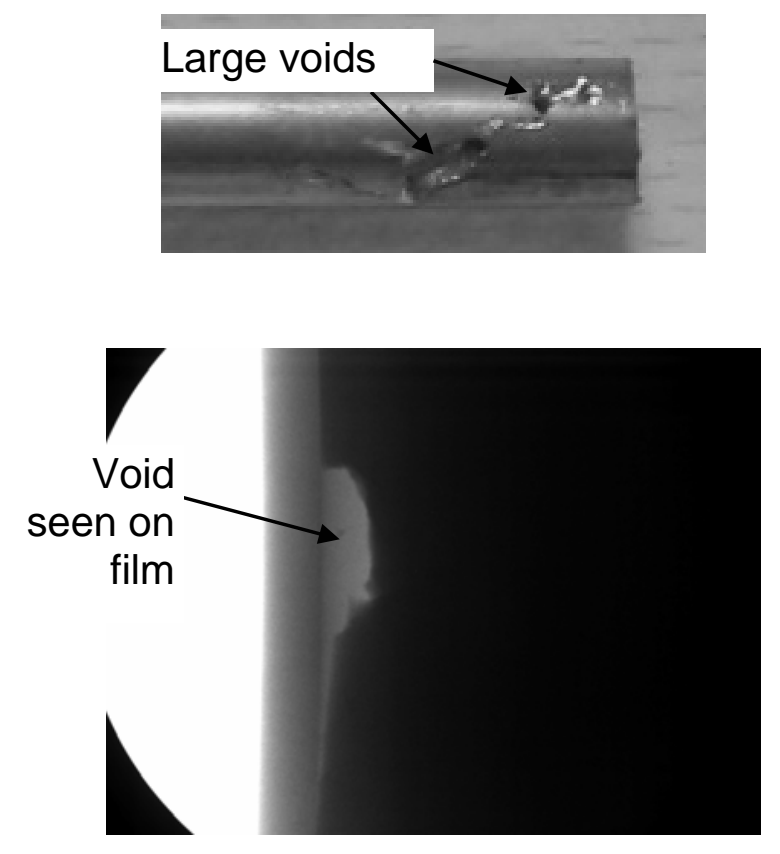

Figures 21(c) and 21(d) Large void revealed by edge-on $X$-rays

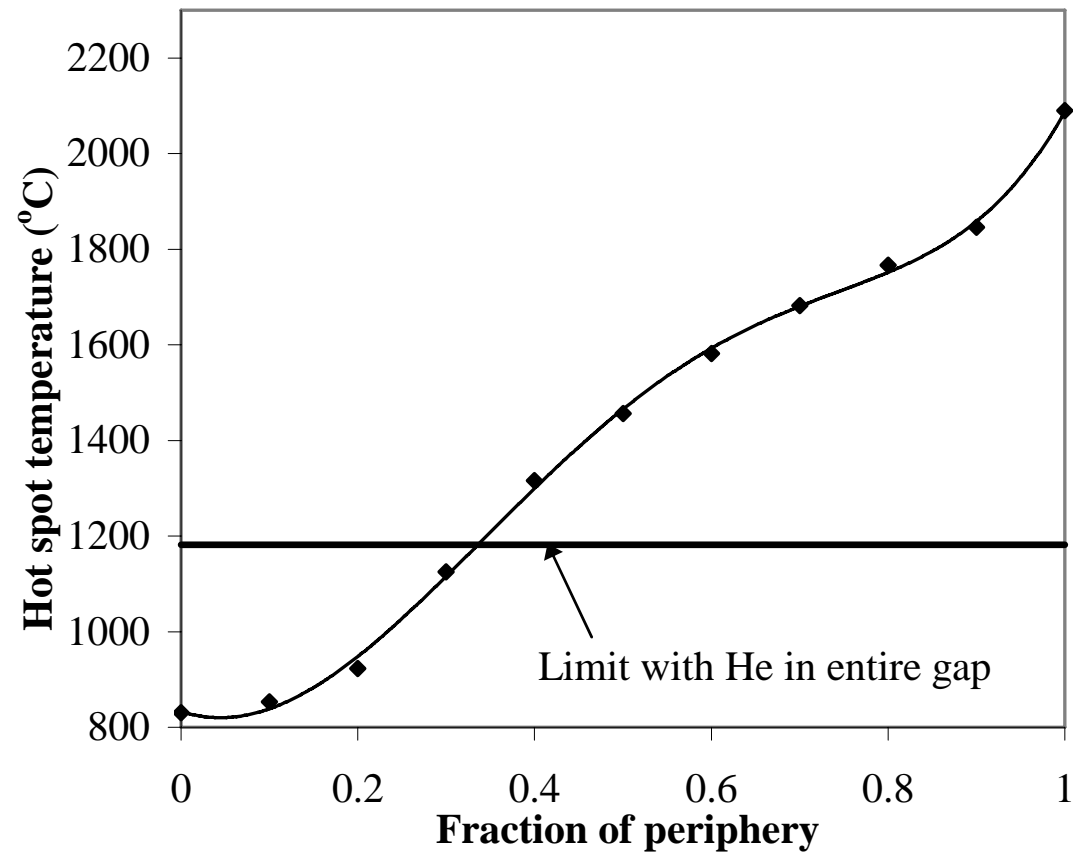

Figure 22 Maximum fuel temperature vs. fraction of the gap periphery that is missing LM (radial gap $\sim 70$ microns, LHR $=270 \mathrm{~W} / \mathrm{cm}$ ). Void height $=1 \mathrm{~cm}$ 


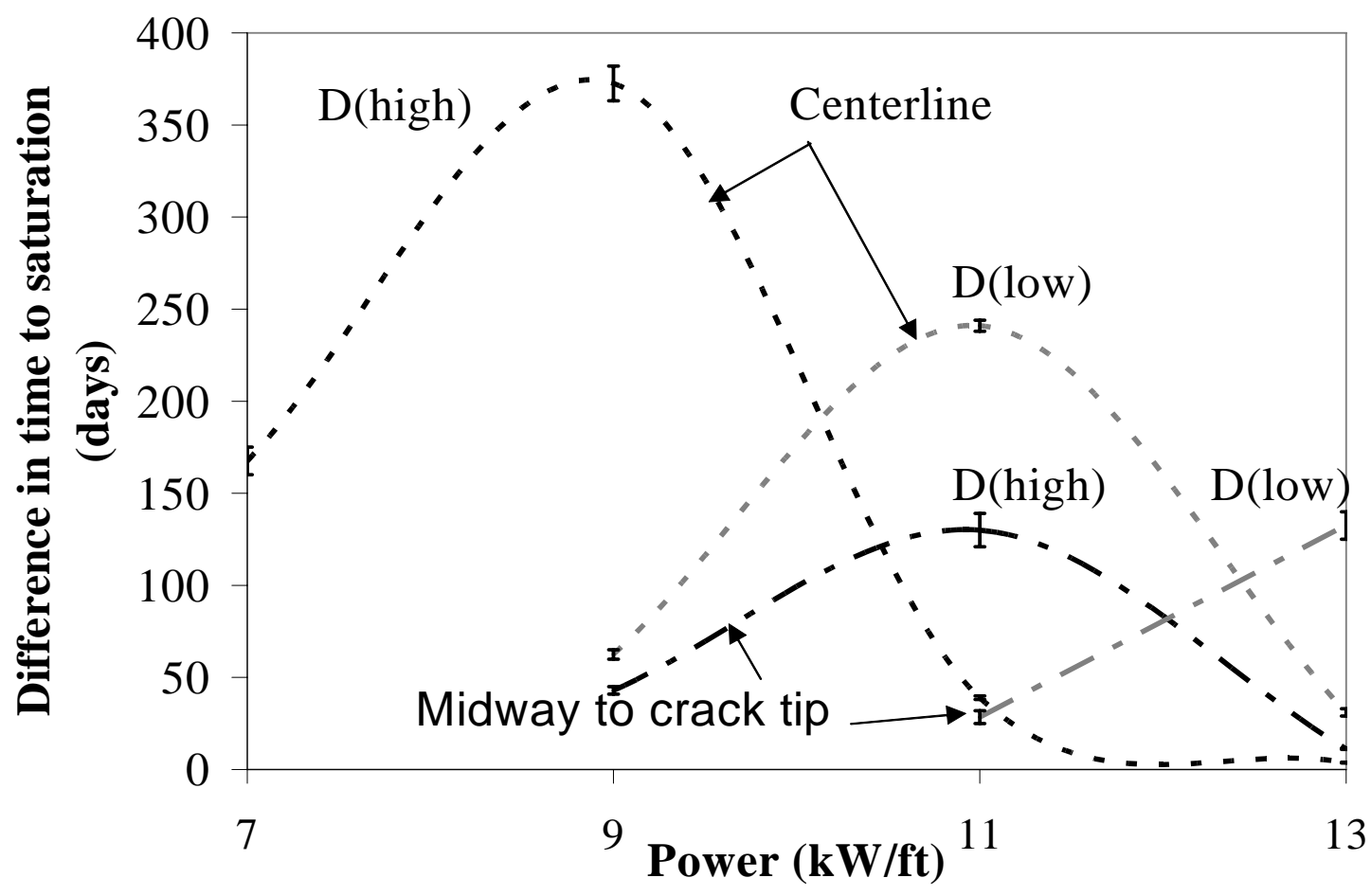

Figure 23 Difference in time for grain boundary saturation with fission gas between He- and LM-bonded fuel cladding gaps

- - - - - - Grain boundaries at fuel centerline

-. - - . Grain boundaries at fractional radial location $\mathrm{r} / \mathrm{R} \approx 0.34$

Results for two formulas for the diffusivity of fission gas in the $\mathrm{UO}_{2}$ lattice (from Ref 4) 


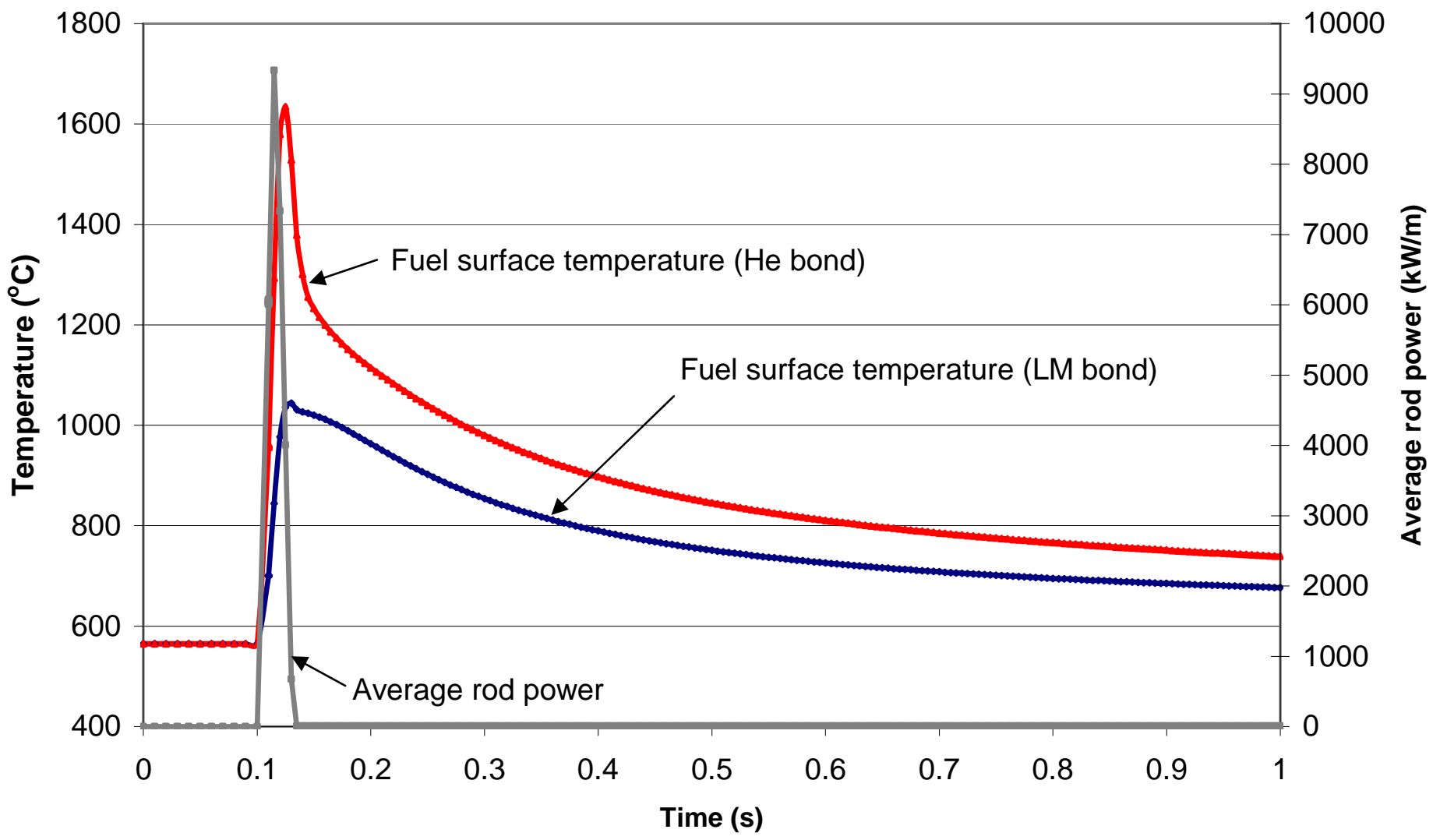

Figure 24 Effect of replacing He in the gap with $L M$ on the fuel surface temperature during a 10 millisecond HZP RIA 